\title{
La sostenibilidad de la náutica de recreo. Estudio de caso del fondeo de las embarcaciones en Jávea (Alicante)*
}

\author{
The sustainability of recreational boating. The case study of anchoring boats in Jávea \\ (Alicante)
}

Gaetano Cerchiello. Universidad de Alicante, España. gaetano.cerchiello@ua.es

\section{RESUMEN}

El fondeo de las embarcaciones de recreo es una de las múltiples presiones que afectan a los ecosistemas marinos del litoral mediterráneo. Este trabajo analiza, por una parte, los impactos económicos y sociales de la náutica de recreo. Por la otra incide en su sostenibilidad ambiental, centrándose en los perjuicios que provoca la acción del anclaje en las praderas marinas. Para ello se estudia el caso específico del litoral de Jávea, donde el tráfico de las embarcaciones de recreo ha alcanzado un elevado grado de saturación en los últimos años. Se examinan las medidas que se han tomado en el municipio alicantino, en el contexto de las experiencias que se están llevando a cabo en otros destinos del Mediterráneo Occidental. La investigación finaliza con una serie de recomendaciones de ámbito local. Se considera que dichas acciones ayudarían a reducir los daños ambientales de esta creciente práctica turística.

Palabras claves: impactos turísticos, turismo náutico, ecosistemas marinos, desarrollo sostenible, boyas de amarre

\section{ABSTRACT}

The mooring of recreational boats is just one of the many pressures suffered by the marine ecosystems of the Mediterranean coast. On the one hand, this study analyses the economic and social impacts of nautical tourism. On the other, it addresses the environmental sustainability, focusing on the damage caused by boat anchoring on seagrass beds. The specific case of

\footnotetext{
* Este artículo forma parte de una investigación realizada en verano de 2017 el marco de un convenio entre la Agència Valenciana del Turisme y la Universidad de Alicante. El autor quiere dar las gracias a: Ángel Sánchez Pardo, del Departamento de Analisis Geogràfico Regional I Geografia Fisica de la Universidad de Alicante; Gabriel de Sandoval, ya Presidente de la FEAPDT; Xavier Pascual, Presidente del IROX (Jávea); Juan Fontes, gerente de la empresa Marina Nou Fontana (Jávea); José Ángel Estalrich, gestor del “Restaurante Sur" (Jávea); Gustavo Baldassari, del Club de Buceo “La Rana” (Jávea).
} 
the coastline of Jávea has been studied for this purpose; recreational boat traffic has reached massive proportions in this area in recent years. The paper analyses the measures taken by this municipality in the light of the action taken in other destinations of the Western Mediterranean. The research concludes with a number of recommendations at a local level which may help to minimise the environmental damage caused by this growing tourist practice.

Keywords: tourist impacts, nautical tourism, marine ecosystems, sustainable development, mooring buoys

«Half my life's in books written pages live and learn from fools and from sages»

(Dream on, Aerosmith, 1973)

\section{INTRODUCCIÓN: OBJETIVOS, ESTRUCTURA Y METODOLOGÍA DEL TRABAJO}

La presente investigación se ha concebido con el objetivo general de desarrollar un protocolo de recomendaciones de ámbito local que permitan compatibilizar los beneficios socioeconómicos asociados a la náutica de recreo con las afecciones ecológicas que provoca el fondeo de las embarcaciones. El estudio, por tanto, no incide en la cuestión relativa a la sostenibilidad de los puertos deportivos, que por su complejidad merece un estudio específico aparte.

De acuerdo con este planteamiento, el escrito consta de cuatro apartados, además de esta introducción y las conclusiones finales. El primero hace un breve análisis de la evolución de la náutica de recreo en España, con especial referencia a la Com. Valenciana y la provincia de Alicante. Para ello se han utilizado los indicadores tradicionales que proporcionan la Federación Española de Asociaciones de Puertos Deportivos y Turísticos (en adelante, FEAPDT) y la Asociación Nacional de Empresas Náuticas (en adelante, ANEN): instalaciones náutico-deportivas, matriculación de las embarcaciones, precios de venta y de alquiler de los amarres. El segundo apartado destaca los efectos económicos y sociales de la náutica de recreo, así como su impacto en el ámbito de la actividad turística. A continuación se indaga en la sostenibilidad ambiental, haciendo sobre todo hincapié en los daños que causa la acción del anclaje a las praderas marinas. El cuarto y último apartado se centra en el análisis de las medidas adoptadas en el municipio alicantino de Jávea, donde la náutica de recreo se ha convertido en una práctica masiva y generalizada. Finalmente, se aportan unas breves consideraciones, a la vez que se plantea la adopción de algunas acciones factibles y coherentes de ámbito local, con el fin de reducir las presiones ambientales de la náutica de recreo sin perjuicio de los beneficios socioeconómicos.

En cuanto a la metodología, el trabajo de investigación ha abarcado dos principales tareas. La primera fue la recopilación y el análisis de la producción científica sobre el objeto de estudio. Entre otros aspectos, la labor se ha centrado en conocer las políticas y estrategias que se han emprendido en otras áreas del litoral mediterráneo occidental, especialmente en algunas localidades italianas y la rivera francesa. La segunda tarea se ha basado en un trabajo de campo en el ámbito del área geográfica de estudio. Ante todo se han realizado entrevistas a representantes de distintos ámbitos: político, empresarial, científico, social, a la vez que se 
han contactado numerosos buceadores y patrones de embarcaciones locales. Además, aprovechando la celebración del Mediterrània Jávea Forum Destins Sostenible a finales de octubre de 2017, se han entrevistado varios ponentes procedentes de distintas localidades costeras del Mediterráneo. Todas las conversaciones se han desarrollado con el objetivo de recabar datos de primera mano de quienes viven más de cerca esta realidad. Los diferentes puntos de vistas han permitido mejorar los conocimientos específicos y profundizar en los aspectos técnicos del objeto de estudio. Las conversaciones con los patrones de embarcaciones locales, por ejemplo, han permitido recabar su visión acerca del uso de las áreas reguladas de fondeo, además de destacar los rasgos específicos de las principales zonas de fondeo del área objeto de estudio. Las aportaciones de los buceadores, por su parte, han sido clave para profundizar en las características técnicas de las llamadas boyas ecológicas y sus ventajas con respecto a las boyas tradicionales. Además de las entrevistas, se han realizado tres observaciones de campo a bordo de una lancha motora, siempre en compañía de algunos buceadores, junto a numerosas observaciones desde el ámbito terrestre. Se trataba de obtener una estimación orientativa del movimiento de las embarcaciones en las áreas de mayor concentración. Esta labor se justifica por la ausencia de datos cuantitativos sobre las operaciones de fondeo en el litoral de Jávea. Las observaciones llevadas a cabo han sido útiles también para valorar la eficacia de las áreas reguladas de fondeo y a la postre detectar algunas anomalías tanto en la instalación como en su específica gestión.

\section{LA EVOLUCIÓN DE LA NÁUTICA DE RECREO EN ESPAÑA}

Aunque no exista en la literatura un consenso generalizado, la náutica de recreo podría definirse como la actividad relacionada con el uso y disfrute de las embarcaciones con fines deportivos o recreativos, incluyendo tanto a las embarcaciones de uso particular como aquellas que gestionan las empresas de chárter. Su fomento en España se dio a partir de los años 1960, en sintonía con el creciente protagonismo del país en el turismo internacional (Esteban, $1998,15-22)$. Durante esa década también se aprobaron las primeras disposiciones legislativas específicas sobre el sector. El Decreto 735 del 24 de marzo de 1966 (BOE, no 79, 2 de abril de 1966) definió el puerto deportivo como aquel destinado al «atraque, amarre y despacho portuario y aduanero de embarcaciones deportivas de todas clases». El texto legislativo destacaba el «auge» y la "expansión» que habían adquirido tanto el deporte náutico como «la afluencia turística interior y exterior realizada a través de la utilización de embarcaciones menores». En cuanto a la provincia norte de Alicante, se suceden en ese transcurso las concesiones del Club Náutico de Jávea (1963), el Puerto Luis Campomanes de Altea (1964) y el Club Náutico de Denia (1967). A finales de esa década, se otorgaron también las concesiones administrativas del Club Náutico de Benidorm y el Club Náutico Les Basetes de Benissa (Celdrán, 2016).

En el último cuarto de siglo pasado, el número de puertos deportivos, puertos turísticos o instalaciones náutico-deportivas, esto es, los lugares donde se albergan las embarcaciones utilizadas para la náutica deportiva y de recreo, fue creciendo en España de manera exponencial, especialmente en la vertiente mediterránea (Esteban, 2003). De acuerdo con las estimaciones de la FEAPDT, el país contaba en 1976 con un total de 131 puertos. A principios del nuevo siglo, en 2003, ya se contabilizaban 274 (gráfico 1). 
Los últimos datos relativos al 31 de diciembre de 2015 informan que en España hay 375 puertos deportivos, por un total aproximado de poco menos de 135 mil amarres (gráfico 2). El incremento fue muy sostenido hasta 2008. Con el comienzo de la crisis económica, el ritmo de crecimiento decayó sensiblemente a causa de la reducción de las inversiones en infraestructuras (Cabrera, 2011). Entre los años 2009 y 2015, el aumento medio anual en términos de amarres fue del 1\%, frente al 5,4 del sexenio anterior. La pauta dominante de los últimos años ha sido "remodelar y ampliar las actuales instalaciones en lugar de construir nuevas», a la vez que ha aumentado el tamaño medio de los amarres (FEAPDT, 2015). A consecuencia de la crisis, el sector entró en una fase de fuerte recesión (Lam-González et al., 2017). La contracción de la demanda tuvo un efecto «devastador» en el contexto nacional, de acuerdo con la variación de los principales indicadores de la industria (Landaluce, 2012). La matriculación de las nuevas embarcaciones, así como los precios medios de alquiler y cesión de amarres, fueron bajando considerablemente.

En cuanto a la matriculación, ésta decayó a una media interanual del 17,8 por cien entre 2007 y 2013, pasando de 12.600 a 3.900 embarcaciones, según datos de la ANEN (gráfico 3). El retroceso fue generalizado, afectando a las embarcaciones de todas las esloras y distintas tipologías (motor, vela, neumáticas plegables, neumáticas semirrígidas, etc.). El punto de inflexión se produjo solamente a finales de octubre de 2013. La exención del Impuesto Especial sobre Determinados Medio de Transporte (IEDMT) para el chárter náutico puso fin al «ciclo de la caída» del sector (ANEN, 2014). En efecto, la cifra anual de las embarcaciones matriculadas en España ha vuelto a crecer, aunque siga lejos de los valores anteriores a la crisis.

Gráfico 1. Evolución del número de puertos para uso deportivo y recreativo en España* $(1976,1987,1992,2003-2015)$
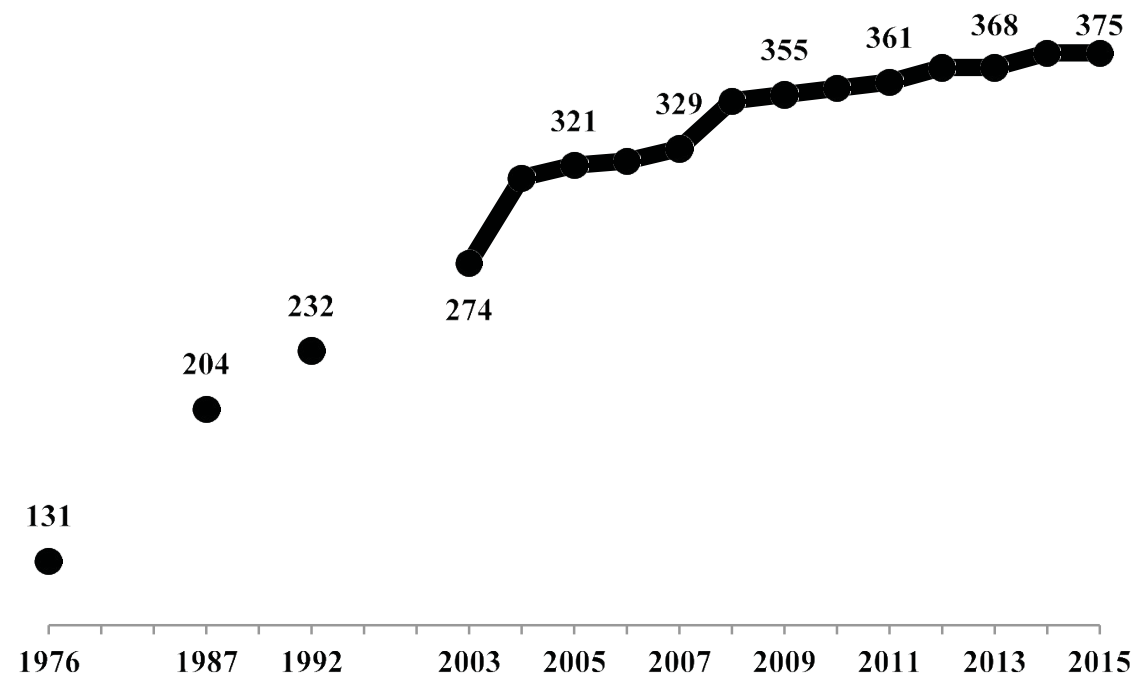

Fuente: FEAPDT, Informe Anual, 2007-2015

* A partir de 2014 dicha fuente es bianual. A día de hoy (10 de junio de 2018), todavía no se ha publicado el informe relativo a los años 2016-2017 
Gráfico 2. Evolución del número de amarres para uso deportivo y recreativo en España Miles de unidades $(1976,1987,1992,2003-2015)$

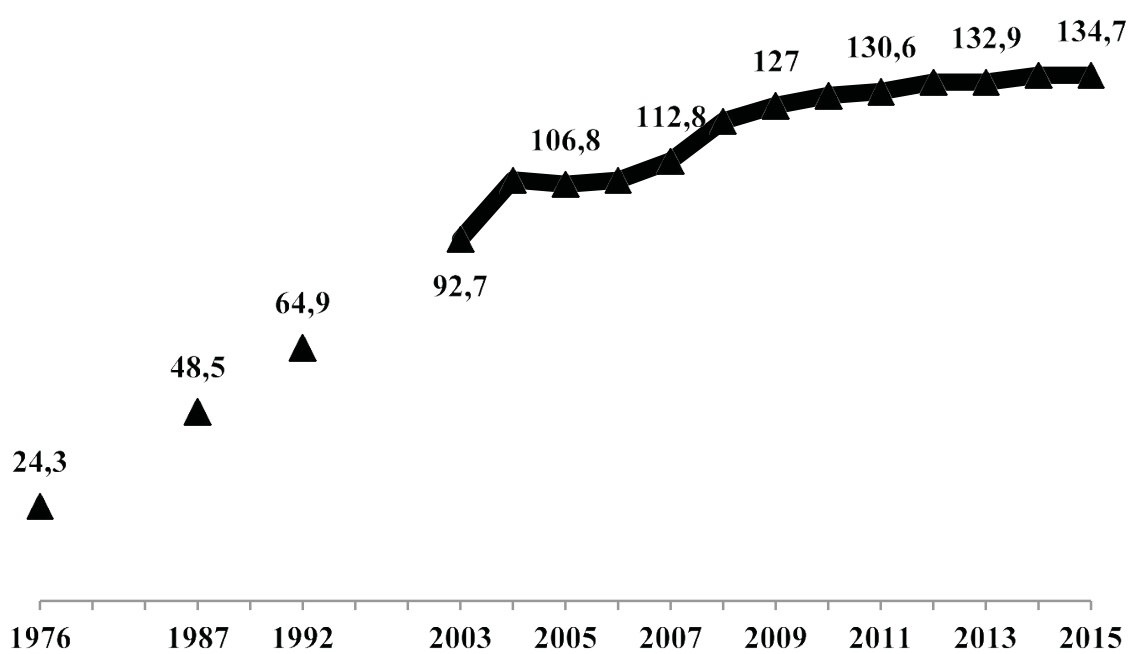

Fuente: FEAPDT, Informe Anual, 2007-2015

Gráfico 3. Evolución de la matriculación de embarcaciones de recreo en España*

Miles de unidades (2005-2017)

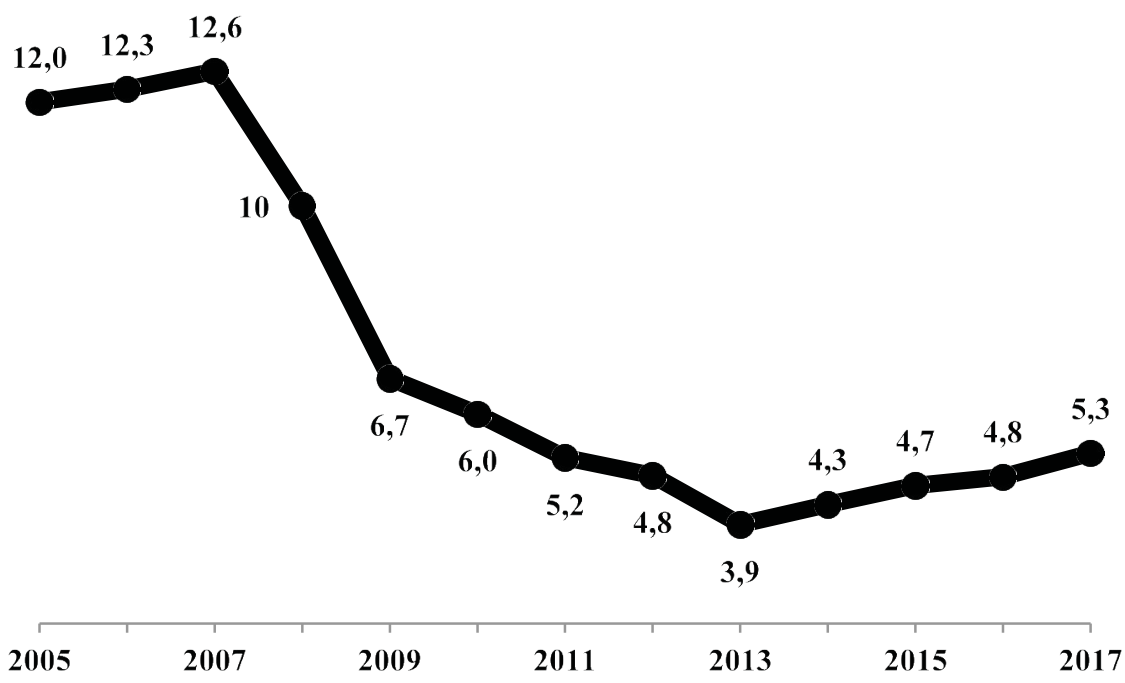

Fuente: elaboración sobre datos de la ANEN (http://www.anen.es; último acceso 10 de junio de 2018)

* Los datos se refieren al conjunto de las embarcaciones (uso particular y chárter) e incluyen las motos de agua

Si el análisis se centra en la evolución de los precios de los amarres, el diagnóstico resulta muy parecido. El gráfico 4 muestra claramente la tendencia a la baja de las tarifas de ventas. Entre 2008 y 2013, se estima una caída acumulada en España de poco menos del 40\%. En el caso de los puertos de la Comunidad Valenciana, la caída media de los precios de cesión fue incluso superior a la media nacional (-47\%). Los efectos se hacen sentir en las instalaciones 
de la Costa Blanca, así como en el resto de las instalaciones de la Comunidad Valenciana. Los importes han seguido bajando también en el último bienio (-21,1\%). A nivel nacional, por el contrario, parece perfilarse un cambio de tendencia. En otras áreas del país, las tarifas en el último bienio (2013-2015) han vuelto al alza. En el País Vasco y Baleares, por ejemplo, han subido respectivamente alrededor del 46 y 23 por cien.

A razón de ello, el nivel medio de los precios en la provincia de Alicante se sitúa en la actualidad por debajo de los valores nacionales, al contrario de lo que ocurría antes de la crisis. En lo referente a los precios medios de alquiler, el escenario se muestra más favorable (gráfico 5). Las repercusiones de la crisis fueron inferiores, tanto en la magnitud de los valores como en la duración de la coyuntura. La recuperación es patente. En los puertos de la CCAA Valenciana, los importes han vuelto casi a los niveles de 2008. En la provincia de Alicante, las tarifas han subido más del 50 por cien en los últimos dos años, aunque siga el saldo negativo con respecto a los valores anteriores a la crisis $(-20,3 \%)$. A la hora de evaluar las variaciones de los importes de los amarres, sean de compra o alquiler, hay que tener en cuenta que los valores que se aportan hacen referencia a los precios medios. Luego, en realidad, suele haber muchas diferencias no sólo entre provincias y comunidades autónomas -los precios en Galicia, por ejemplo, suelen ser muchos más económicos que en otras áreas geográficas, como el caso de las Baleares- sino incluso en el mismo término municipal. En Jávea, por ejemplo, son incomparables los precios que se ofrecen en el Puerto Deportivo y en la Marina Fontana, las dos instalaciones del municipio objeto de estudio, siendo muy inferior los de la primera entidad. La diferencia estriba en la calidad de las instalaciones y los servicios que ofrecen cada uno, "al igual de lo que ocurre con los alojamientos hoteleros» (Fontes J., gerente de la empresa Marina Nou Fontana, comunicación personal, 26 de octubre de 2017).

Gráfico 4. Evolución de los precios medios de cesión de amarres para uso deportivo y de recreo en España, CCAA Valenciana y Provincia de Alicante

Precios nominales en miles de euros por $\mathrm{m}^{2}$ (2008-2015)*

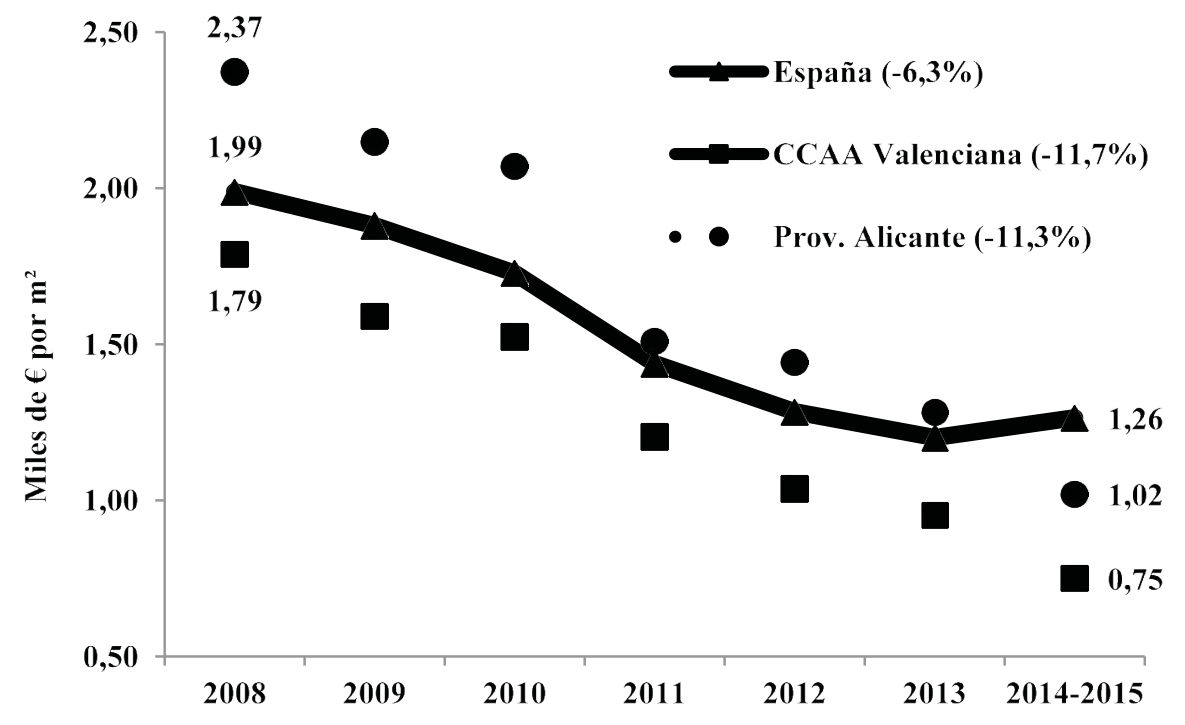

Fuente: elaboración sobre datos de la FEAPDT, Informe Anual, 2007-2015

* Entre paréntesis, la variación interanual 2008-2015. Los PVP se refieren a los amarres de entre 4 y $60 \mathrm{~m}^{2}$ 
Gráfico 5. Evolución de los precios medios de alquiler de amarres para uso deportivo y de recreo en España, CCAA Valenciana y Provincia de Alicante

Precios nominales en euros por $\mathrm{m}^{2}(2008-2015)^{*}$

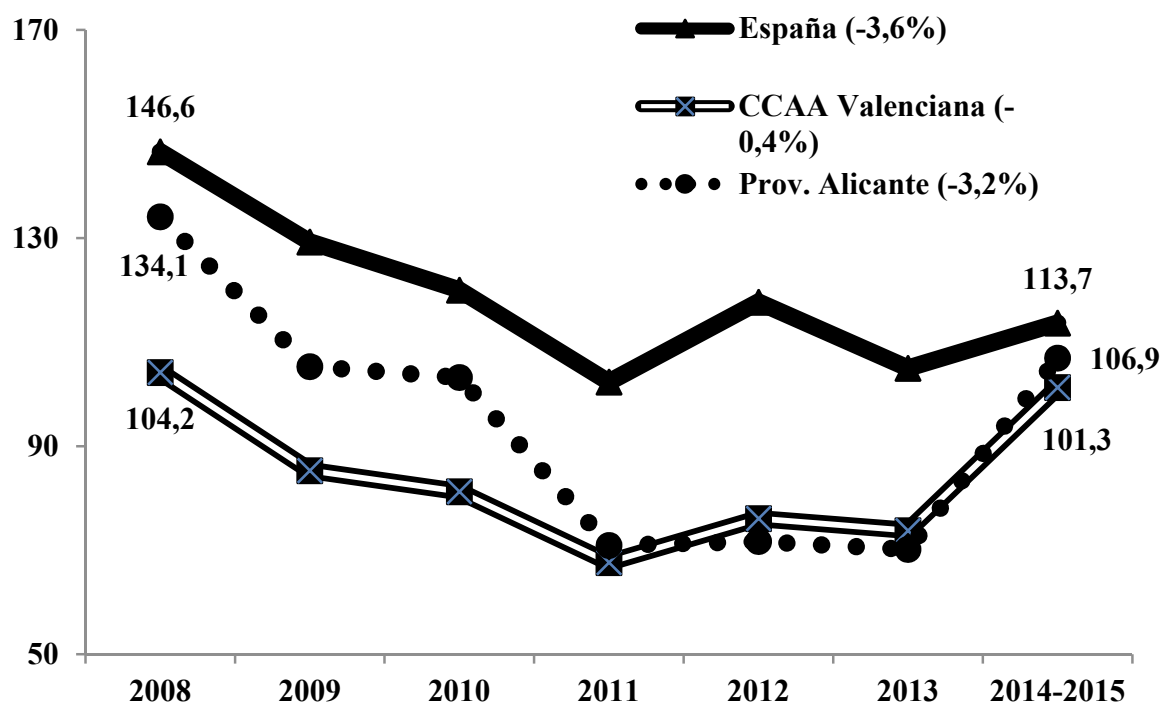

Fuente: elaboración sobre datos de la FEAPDT, Informe Anual, 2007-2015

* Entre paréntesis, la variación interanual 2008-2015. Los PVP se refieren a los amarres de entre 4 y $60 \mathrm{~m}^{2}$

\section{LOS IMPACTOS SOCIOECONÓMICOS}

Desde una perspectiva meramente económica, la náutica de recreo genera numerosos beneficios (Luković, 2013; Kovačić et al., 2011; Alcover et al., 2011; Contini, 2010; Méndez, 2007). Todos los estudios que tienen por objeto valorar el impacto económico de la náutica de recreo coinciden especialmente en señalar el efecto multiplicador de otros servicios. Alejandro Landaluce hace hincapié en que se trata de una industria que implica un «elevado» consumo de servicios intermedios. El antiguo director general de la ANEN (Landaluce, 2012, 69) afirma que «una embarcación de recreo requiere motores, generadores, electrónica, componentes poliméricos y un sinfín de elementos que provienen de otras industrias auxiliares y que, sin la existencia de los primeros, no tendrían cabida».

La ANEN estima que la náutica de recreo en España generó de forma directa un Valor Añadido Bruto (VAB) de 1.079 millones de euros en 2009. Según esta fuente, los multiplicadores asociados al impacto del sector indican que el VAB experimenta un incremento que finalmente más que quintuplica $(5,27)$ su efecto directo inicial. En cuanto a la generación de empleo, se considera que la náutica de recreo contribuía al desarrollo del mercado laboral con un total de 107.434 puestos de trabajos, cuyo desglose se muestra en la tabla 1 . El efecto multiplicador aplicado al sector en el mercado laboral sería por tanto 6,71, es decir, por cada 100 puestos directos se crearían 671 empleos indirectos. Según la misma entidad, el efecto multiplicador de la náutica de recreo en el mercado laboral español en 2005 era incluso más elevado $(7,6)$. 
Tabla 1. Impacto de la náutica de recreo en España (2009)

\begin{tabular}{|c|c|c|c|c|c|}
\cline { 2 - 6 } \multicolumn{1}{c|}{} & Efecto Directo & Multiplicador & Efecto Total & Efecto Indirecto & $\begin{array}{c}\text { Efecto } \\
\text { Inducido }\end{array}$ \\
\hline $\begin{array}{c}\text { VAB } \\
\text { (millones de } € \text { ) }\end{array}$ & 1.079 & 5,27 & 5.690 & 3.640 & 971 \\
\hline Empleo (personas) & 16.000 & 6,71 & 107.434 & 69.502 & 21.932 \\
\hline
\end{tabular}

Fuente: ANEN (2012) y Landaluce (2012)

A partir de otra investigación sobre una muestra de 44 puertos deportivos catalanes, se estima que por cada 1.000 amarres se crearían 44 puestos de trabajo directo y 396 empleos indirectos (Adame, 2009). De acuerdo con esta fuente, por cada 10 empleos directos en un puerto se generarían 90 puestos de trabajo en actividades indirectas, esto es, el factor multiplicador del sector en el ámbito laboral sería 9: por cada puesto directo en una instalación náutica se generarían 9 empleos en actividades indirectas. La figura 1 muestra la distribución de los puestos de trabajo según el tipo de actividad desempeñado.

Figura 1. Impacto de la náutica de recreo en Cataluña

Distribución de los puestos de trabajo generados según actividad-sector

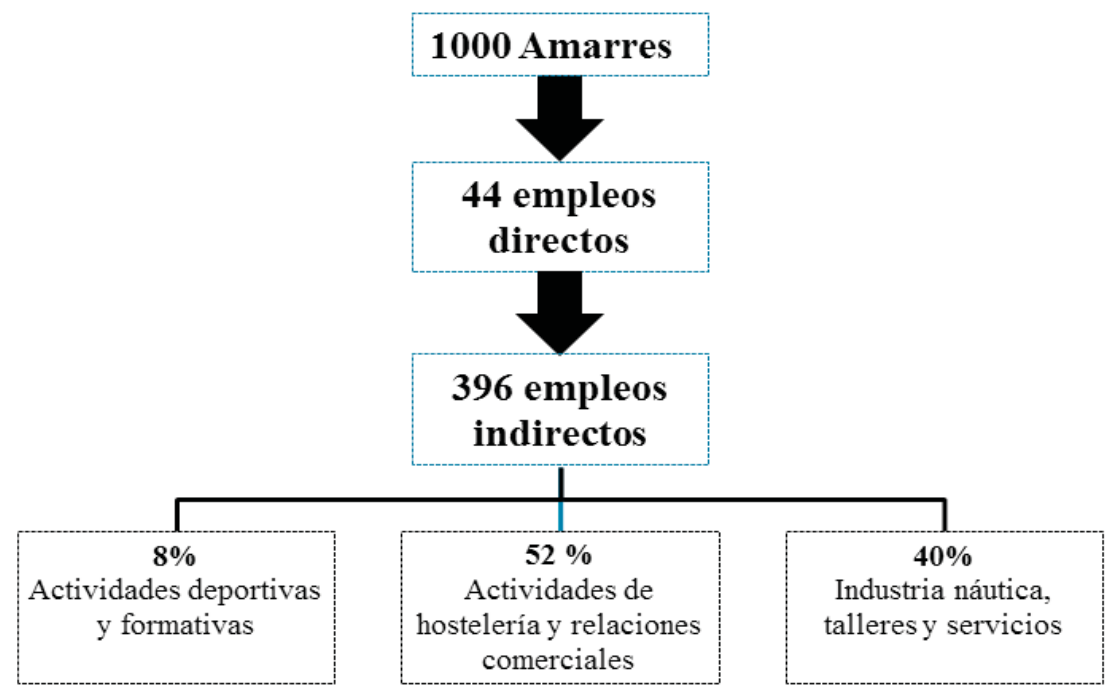

Fuente: elaboración sobre información de Adame (2009)

La disparidad de cifras que suelen aparecer en este tipo de estudios quizás se debe a que sigue habiendo una cierta "ausencia de sistematización en el tratamiento y elaboración» de los datos relativos a la náutica deportiva, tal y como destacaba hace unos años Vicent Esteban $(2003,18)$. El mismo autor recuerda que el volumen de empleo generado por una instalación náutica, bien directa o indirectamente, varía en función del ámbito geográfico, las dimensiones de los puertos, el tamaño de los amarres, etc. Dicho de otra manera, no habría que extrapolar los resultados de un estudio fuera de los ámbitos donde ha sido realizado -por ejemplo, Cabrera, 2011-, porque hay muchas variables a tener en cuenta. En cualquier caso, 
y más allá de estas importantes consideraciones, los rendimientos socio-económicos de la náutica de recreo son evidentes. Sus efectos transversales son muy elevados, especialmente si se comparan con los que generan otras modalidades turísticas. Sirva este breve ejemplo: el efecto multiplicador del turismo de cruceros en Barcelona, en el ámbito del mercado laboral, es "tan sólo" 0,68 (Port de Barcelona, 2014). La propia patronal del sector crucerístico (CLIA, 2015) calcula que esta actividad genera en España un total aproximado de poco más de 28.500 empleos, frente a los más de 100 mil que produce la náutica de recreo según las estimaciones de la ANEN ${ }^{1}$.

En lo referente al área geográfica de este estudio, el ejemplo más llamativo procede del puerto deportivo la Marina Fontana. La empresa concesionaria Marina Nou Fontana se compone de un total de 13 empleados, a los que hay que añadir otros 2 que se incorporan en la época estival. No obstante, según las cifras que aporta la propia entidad, el puerto genera no menos de 100 puestos de trabajos, incluyendo los buceadores profesionales de los 7 clubes de buceo que realizan su actividad desde dicha instalación (Fontes, 26 de octubre de 2017). De acuerdo con esta fuente, cerca del $80 \%$ de las inmersiones que se hacen en el litoral de Jávea, lo que en términos numéricos serían unas 20 mil inmersiones anuales, salen en lanchas desde la Marina Fontana. Durante el año 2016, dicha instalación registró en total un movimiento estimado de 4 mil entradas de embarcaciones, incluyendo aquellas que procedían tras haber efectuado operaciones técnicas de mantenimiento y botaduras.

Pero al margen de estos beneficios, cabe añadir otros aspectos no menos importantes de cara al desarrollo turístico de los destinos costeros. La náutica de recreo, y en general las actividades asociadas al disfrute activo del mar, desempeñan una notable función en la desestacionalización de la actividad turística (Vera y Baños, 2010; Besteiro, 2004; Ferradás, 2001). Este escenario se hace muy evidente en la comarca alicantina de la Marina Alta, cuyo modelo turístico se caracteriza por su «elevada» estacionalidad (Vera, 1999). Otros estudios también han recalcado la complementariedad del turismo náutico, en virtud de los elementos añadidos que aporta al atractivo básico de los destinos litorales (entre otros, Espejo, 2011; Favro et al., 2008; Antón, 2004; Ferradás, 2002). La amplia variedad de actividades náutico-deportivas contribuye a la diversificación del modelo turístico tradicional y desempeña un importante papel dinamizador, sobre todo en el ámbito de los destinos consolidados (Celdrán, 2016).

El turismo náutico, además, no sólo «diversifica y especializa la oferta convencional», sino es susceptible de atraer amplios grupos de demanda con una «componente finalista en su motivación» (Vera, 2005). Y aunque se haya asociado en el pasado únicamente a una demanda de elevado poder adquisitivo, la situación de hoy en día es mucho más compleja. El variado y creciente espectro de modalidades que las componen hace que el turismo náutico se dirija a un público muy diversificado, social y económicamente. Incluso la náutica de recreo, que históricamente ha ostentado el cartel de actividad elitista (Gómez, 2012; Panzeri, 2008), ya no es una exclusividad de las clases altas. La oferta de embarcaciones, y la consecuente oferta de amarres, abarcan una amplia gama de alternativas, desde los mega-yates hasta las pequeñas neumáticas plegables. Por otro lado, las empresas de chárter permiten el disfrute de la

1. Cabe precisar que los datos relativos al turismo de cruceros hacen referencia al 2015 , mientras que los de la náutica de recreo proceden de un estudio de 2009. 
navegación sin la necesidad de invertir grandes sumas por la compra de una embarcación, siendo además un soporte para la práctica de otras actividades relacionadas con el disfrute activo del mar: buceo, snorkel, pesca deportiva, etc. (Alcover et al., 2011). A razón de todo ello, no debe de sorprender que muchos estudiosos que se muestran muy críticos con la sostenibilidad ambiental de la náutica de recreo, no dudan al mismo tiempo en reconocer su «elevado» y «determinante» papel socio-económico (entre otros, Boudouresque et al., 2008; Cappanera et al., 2008).

\section{LA SOSTENIBILIDAD AMBIENTAL DE LA NÁUTICA DE RECREO}

Si el análisis de los impactos de la náutica de recreo se limitara a las dimensiones sociales y económicas, las conclusiones serían largamente positivas. No obstante, cuando los estudios se centran en valorar también su sostenibilidad ambiental, la perspectiva cambia notablemente. Las afecciones ambientales, paisajísticas y territoriales constituyen la otra cara de la moneda. Estos impactos tienen una doble vertiente. Por un lado están los perjuicios que causan los puertos deportivos. Por el otro están los que generan las propias embarcaciones durante la navegación, especialmente cuando fondean en proximidad de la costa. Como se ha señalado anteriormente, este trabajo se centra en el segundo aspecto. Los efectos inherentes a las instalaciones náutico-deportivas son múltiples y atañen a distintos ámbitos (Torres, 2002). Además, estos efectos se manifiestan en dos espacios temporales: la construcción y su posterior funcionamiento. De acuerdo con J. Fernando Vera $(2005,49)$, la implantación de un puerto tiene repercusiones en todos los elementos que, básicamente, configuran el medio costero: la zona marítimo-terrestre, el mar y los fondos marinos. Los puertos deportivos, como otras construcciones costeras, interfieren notablemente en la dinámica litoral: regresión costera, retroceso y pérdidas de playas, además de perjudicar a las praderas marinas (García, 2006; Ruiz et al., 1993; Ruiz y Romero, 2003; Roca et al., 2014). Se trata, en otras palabras, de una problemática distinta que, debido a su complejidad, requiere un estudio por separado.

El fondeo masivo de las embarcaciones de recreo en proximidad de la costa representa una escena casi cotidiana en una infinidad de localidades turísticas del Mediterráneo. En temporada alta, y especialmente los fines de semana, las embarcaciones anclan en las inmediaciones de playas, calas, cuevas y otros espacios naturales resguardados de los vientos dominantes. El principal problema consiste en que estos lugares de gran valor ecológico y paisajístico suelen caracterizarse por su elevada fragilidad y vulnerabilidad. Muchos de ellos son objetivamente muy pequeños y tienen una capacidad de carga muy limitada. El fondeo se ha generalizado con el paso de los años, a medida que se ha ido expandiendo el sector. Para algunos destinos, como el caso del municipio objeto de este estudio, se trata de un fenómeno relativamente reciente. Para otros tiene una larga trayectoria, como el caso de numerosas localidades de la rivera francesa o del noroeste de Italia.

\subsection{Tipología de los impactos ambientales}

Las embarcaciones de recreo generan, básicamente, tres tipos de impactos ambientales: transporte de especies nocivas, contaminación del medio marino y degradación del fondo (figura 2). El primero gira alrededor de la obra viva de las embarcaciones, es decir, la parte 
sumergida de los barcos. Algunos estudiosos concluyen que la náutica de recreo es posiblemente el principal causante de la propagación de especies marinas invasoras (Clark et al., 2011, 1). Como responsables de este fenómeno, se señalan sobre todo a las pequeñas embarcaciones que, debido a su menor velocidad, se convierten en los vectores ideales de la introducción a otras regiones geográficas de organismos muy nocivos para las especies autóctonas, incluyendo el alga Undaria pinnatifida y varios tipos de moluscos, como el Perna viridis y Dreissena polymorpha (Hay, 1990; Power et al., 2004; Padilla, 1996).

Figura 2. Los impactos ambientales de las embarcaciones de recreo

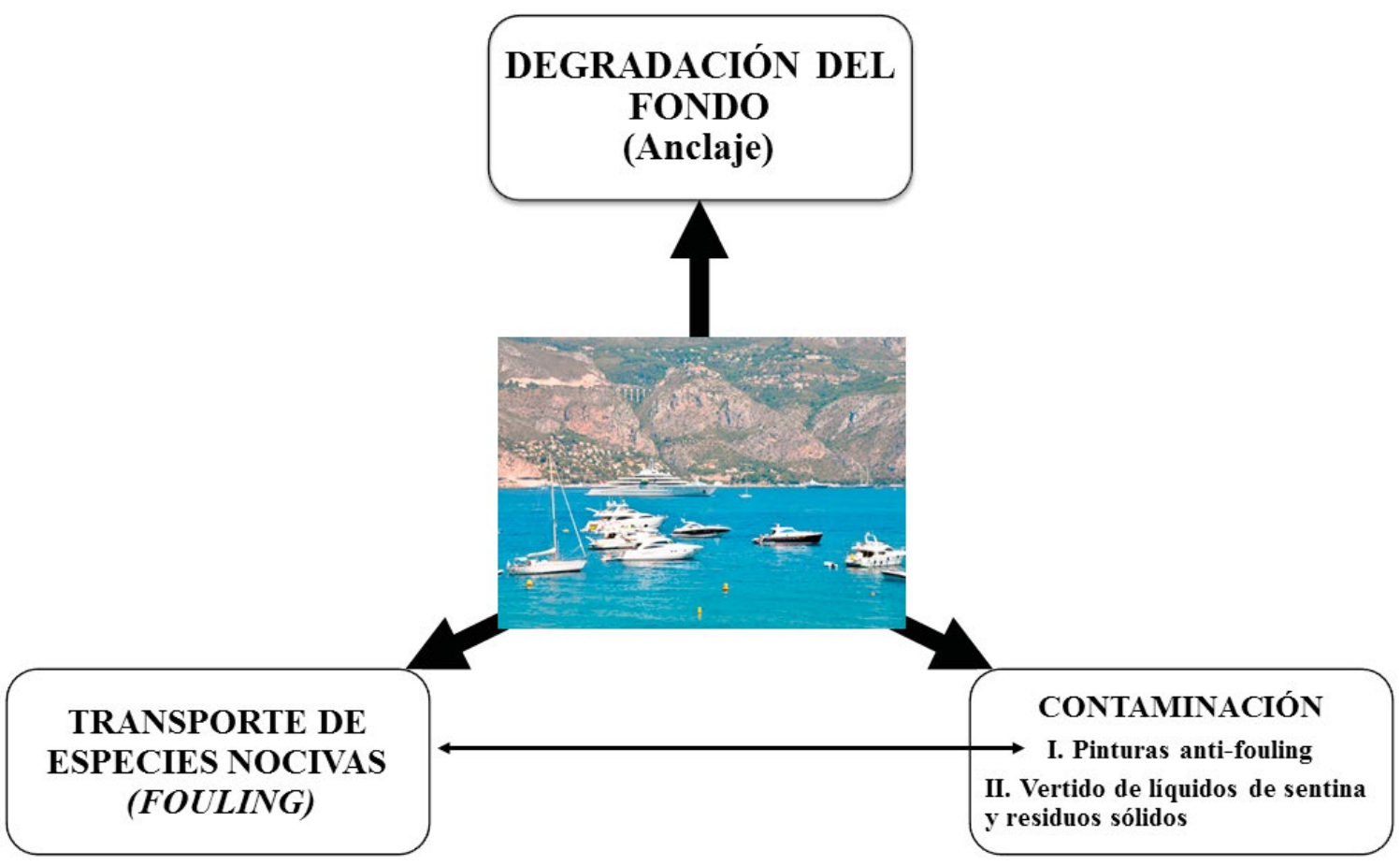

Fuente: elaboración propia sobre información de Boudouresque et al., 2008

En todo caso, la cuestión se presenta muy compleja y genera muchas controversias. La generalización de las pinturas anti-fouling, esto es, las pinturas utilizadas para reducir el proceso de incrustación en la parte sumergida de los barcos, no parece haber solucionado definitivamente el problema, por lo menos hasta la fecha. Es cierto que este tipo de pintura reduce la incrustación (fouling), garantizando con ello un menor consumo de carburante al disminuir la resistencia al avance de los barcos. No obstante, estas pinturas tienen un efecto colateral. Se consideran muy perjudiciales para el medio marino, siendo una importante fuente de contaminación (Floerl, 2002; Dafforn, 2008). Según el Centro de Actividad Regional para el Consumo y la Producción Sostenibles (http://www.cprac.org, último acceso 15 de junio de 2018), una entidad de cooperación internacional a partir de modelos de consumo y producción más sostenibles, las pinturas antiincrustante más difundidas en la actualidad contienen cobre. $Y$ aunque éste sea menos peligroso del arsénico, mercurio, tributilestaño u otra sustancia utilizada en el pasado, sigue siendo tóxico cuando es presente en altas concentraciones, especialmente de cara a los peces y moluscos. 
La contaminación del medio marino se produce también a causa del vertido de residuos domésticos y aguas residuales (Burgin and Hardiman, 2011). En la sentina de los barcos, esto es, en la parte inferior del interior del casco, suelen acumularse diferentes líquidos que se generan durante las operaciones de mantenimiento, reparación o en la propia fase de navegación: aceites, combustibles, detergentes de limpiezas, agua del mar, etc. Esta mezcla, que se conoce como 'líquidos de sentina', puede ser muy contaminante para los ambientes marinos. El problema se genera cuando los usuarios la vacían durante la navegación o, aún peor, durante el fondeo en las inmediaciones de la costa. Todo ello en lugar de utilizar los puntos verdes, esto es, los servicios que suelen ofrecerse en los puertos. Es evidente que este mal hábito afecta no sólo al medioambiente sino también a las actividades relacionadas con el turismo, la pesca o acuicultura que se desarrollen en la zona adyacente ( $\underline{h t t p: / / w w w}$. cprac.org, último acceso 15 de junio de 2018). Otra forma de contaminación se da mediante el vertido de la basura que se genera a bordo de los barcos. Alrededor de $54 \mathrm{Kg}$. de residuos sólidos, por ejemplo, se acumularon en una superficie de poco más de 1 hectárea en la Marine $d^{\prime} E l b o$, una pequeña cala de la Reserva Natural de Scandola (Córcega) donde suelen fondear una multitud de embarcaciones de recreo (Boudouresque et al., 2008, 85). Esta basura (latas, plásticos, papel de aluminio, etc.) se suma a los otros desperdicios que suelen depositarse en el litoral de las localidades turísticas costeras. En el municipio de Jávea (http://www.ajxabia. com, último acceso 20 de junio de 2018), la Primera Jornada Popular de limpieza del litoral, que tuvo lugar el primer domingo de mayo de 2017, significó la recogida de más de $550 \mathrm{Kg}$. y 30 sacos de residuos. Entre el material que se encontró en la costa y los fondos marinos, según información del propio ayuntamiento, había mucho plástico, neumáticos, colillas, plomos e hilos de pesca.

El tercer impacto ambiental lo genera la propia acción de fondear. La producción científica sobre este aspecto es muy extensa, siendo una evidencia del interés y la gran preocupación que suscita (Ganteaume et al., 2005, 148). El fondeo intensivo y desmedido de las embarcaciones de recreo, por medio de anclas o pesos muertos, supone una seria amenaza para la conservación de los ecosistemas marinos costeros (Montefalcone et al., 2013). Para muchos estudiosos, se ha convertido en la causa principal de la alteración y regresión en ámbito local de las praderas de Posidonia oceanica (L.) Delile, 1813, una planta endémica del Mediterráneo (Francour et al., 1999; Milazzo et al., 2004). La Posidonia oceanica habita preferentemente en los substratos blandos, aunque también se puede observar en los fondos rocosos. Se caracteriza por la formación de amplias praderas y por tener un proceso de crecimiento muy lento. En las zonas particularmente protegidas del oleaje, sus hojas pueden llegar a rozar la superficie. Su profundidad máxima varía sobre todo en función de la transparencia del agua, siendo más escasa su presencia a partir de los 35-40 m. de profundidad (Boudouresque et al., 2008, 14). Las praderas de Posidonia constituyen el ecosistema más extendido del litoral del Mare Nostrum y están ampliamente distribuidas en el litoral de la práctica totalidad de los municipios de la provincia de Alicante (Ruiz et al., 2015, 232-234). No obstante, su superficie va disminuyendo progresivamente a causa de la fuerte presión antrópica (Fornes et al., 2006; Pérès, 1984). 


\subsection{Funciones y servicios de la Posidonia oceanica}

La Posidonia oceanica desempeña una función clave en los ambientes marinos costeros, muy similar a la función de las forestas en los ambientes terrestres. No en vano, se trata de una especie protegida. La Unión Europea, a través de la Directiva de Hábitats 92/43 del año 1992 y su posterior adaptación mediante la Directiva 97/62 de 1997, incluye a la Posidonia oceanica como hábitat prioritario a conservar dentro de su territorio (Ruiz et al., 2015, 81). En términos generales, las praderas de Posidonia ejercen cuatro grandes funciones (figura 3 ). Ante todo se destaca su función bioindicadora. Al igual que otras plantas marinas, son muy sensibles a los cambios y perturbaciones de origen antrópico (Milazzo et al., 2002; Donato y Battino, 2009). Por este motivo, se han convertido desde hace años en una valiosa herramienta para obtener una valoración del estado de salud del ambiente marino costero. Entre otros parámetros, proporcionan información sobre la turbidez media del agua, tasa de sedimentación, variación de la salinidad, etc. (Romero et al., 2007; López y Royo et al., 2011; Gera et al., 2012).

Como otras fanerógamas marinas, ejercen un servicio de primaria importancia en los equilibrios ecológicos del sistema litoral (Heck et al., 2003). Producen una enorme cantidad de materia vegetal y son la base de numerosas cadenas tróficas. Constituyen también una importante área de reproducción y primer crecimiento (nursery area), así como un hábitat permanente de numerosísimos organismos vegetales y animales. Más de 400 diferentes especies vegetales y miles de especies animales viven en las praderas de Posidonia, encontrando en éstas protección y cobijo. Además de ser un polo de biodiversidad, la Posidonia oceanica representa un factor importante para la oxigenación del agua. Las cantidades de oxigeno varían en función de la densidad de las praderas y su nivel de profundidad; $1 \mathrm{~m}^{2}$ de pradera situado a $10 \mathrm{~m}$ debajo del nivel del mar puede producir en torno a 14 litros de oxígeno al día (Boudouresque et al., 2008).

Figura 3. Las funciones de las praderas de Posidonia en los equilibrios del medio marino

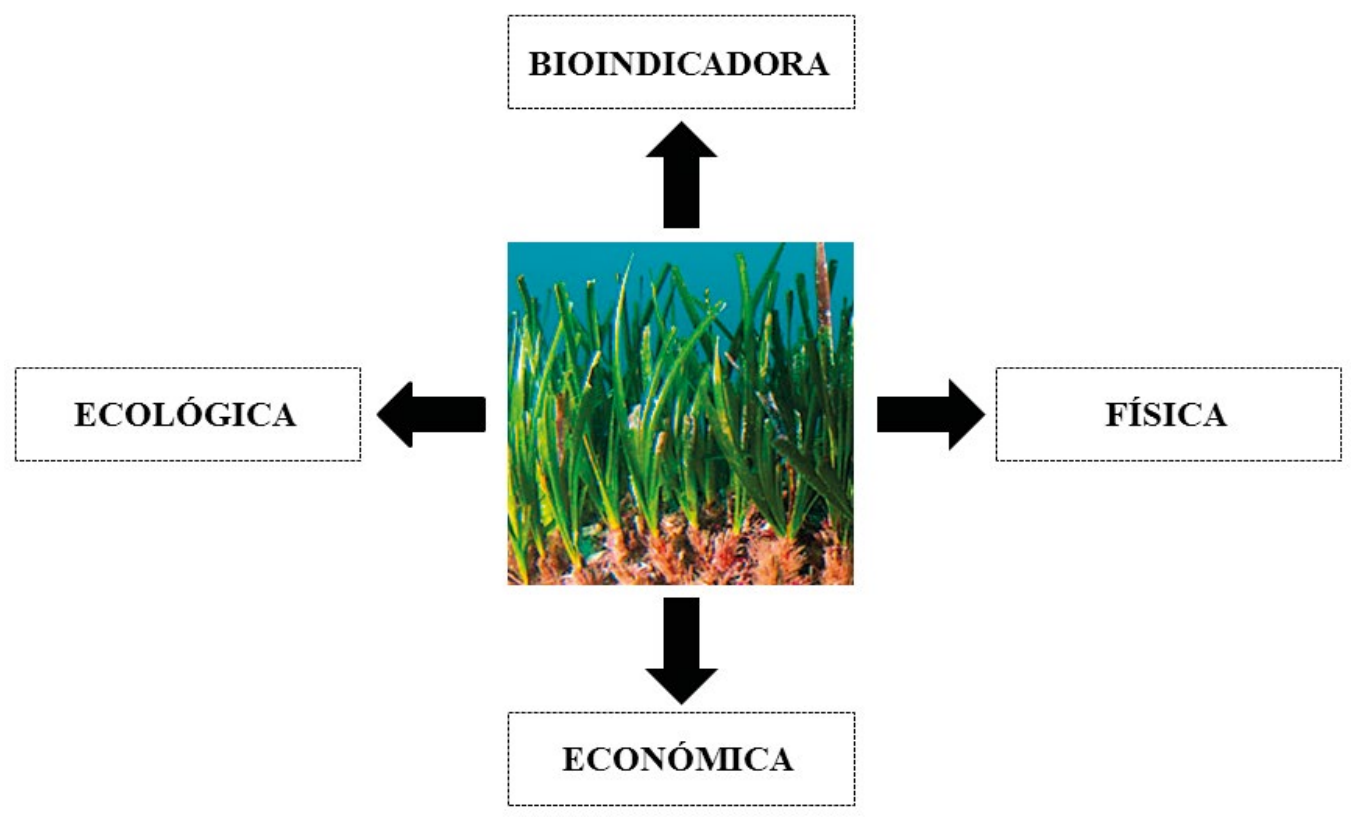

Fuente: elaboración propia sobre información de Boudouresque et al., 2008 
En cuanto a los equilibrios físicos, las praderas de Posidonia favorecen la decantación y sedimentación de las partículas suspendidas en agua y reducen eficazmente el hidrodinamismo, lo que se traduce en una mayor transparencia de las aguas (Gacia y Duarte, 2001). Protegen las playas de los procesos de erosión en buena parte provocados por las actividades antrópicas. La caída cíclica de las hojas, que suelen vivir entre 5 y 8 meses, produce el transporte de la masa vegetal hacia las playas. Aunque suele ser una molestia para los bañistas, estos arribazones representan una barrera natural frente a las olas y contribuyen a estabilizar la línea de costa. El proyecto de investigación europeo Life Posidonia Andalucía estima que una desaparición hipotética de las praderas de Posidonia del litoral mediterráneo andaluz supondría un coste inicial de casi 100 millones de euros tan sólo por el mantenimiento de las playas afectadas por el proceso de erosión.

La importancia que revisten las praderas de Posidonia en los equilibrios ecológicos y físicos del sistema costero se pone de manifiesto, por tanto, también en el ámbito económico (Vassallo et al., 2013). Siendo la base de numerosas cadenas tróficas y nutrición específica de muchas especies animales de interés comercial, incluyendo los crustáceos, aportan un valor económico directo a la pesca. Al mismo tiempo, contribuyen directamente a la calidad del desarrollo turístico gracias a la conservación de la transparencia del agua y al mantenimiento de la dinámica litoral (fijación del sedimento, protección de playas, etc.). De este modo, resulta cuanto menos llamativo el hecho de que las principales amenazas para la tutela de las praderas procedan mayoritariamente de estos dos sectores. A pesar de su prohibición en las inmediaciones de las costas, por ejemplo, la pesca de arrastre se identifica comúnmente como una de las principales amenazas. En la provincia de Alicante, dicha práctica ha sido uno de las causas más importantes de degradación de las praderas a escala regional (Ruiz et al., 2015, 236; González-Correa et al., 2005, 66). Un estudio realizado hace años en el litoral de los municipios de Alicante, Campello, Villajoyosa y Altea, concluía que más del $50 \%$ de las praderas se encontraban degradadas, y que la mitad de ellas lo estaban a causa de la pesca de arrastre ilegal (Ramos et al., 1994).

El desconocimiento y la falta de concienciación de los múltiples beneficios que aportan las praderas de Posidonia al medio marino podrían estar en la base de las conductas poco apropiadas que suelen caracterizar los fondeos de las embarcaciones de recreo. Las investigaciones llevadas a cabo ponen de relieve que buena parte de los navegantes suele ignorar el tipo de fondo donde detienen sus embarcaciones. En el Parque Natural de Cap de Creus (Gerona) se cifra este conjunto en más del 75\% (Lloret et al., 2008, 752). Se trata de un porcentaje muy elevado, aún más teniendo en cuenta que la absoluta mayoría de las embarcaciones allí fondeadas (86\%) suele proceder de los puertos cercanos de Empuriabrava, Rosas y Cadaques. A la "mayoría» de los usuarios de ese paraje, concluyen los investigadores, «no les importa el tipo de fondo donde despliegan el ancla y, en consecuencia, no evitan anclarse en las praderas» (Lloret et al., 2008, 752, traducción del autor).

La importancia de estos ecosistemas contrasta con la falta de sensibilidad hacia su conservación (Vera, 2005, 53). Y dicha falta, lamentablemente, parece ser generalizada. Cerca del $80 \%$ de los turistas alojados en la costa mediterránea andaluz afirma ignorar la existencia de la Posidonia, ya que «nunca ha oído o leído ese nombre» (Life Posidonia Andalucía, 2014, 
57). Esta última fuente también destaca la poca concienciación entre los administradores y empresarios locales, quienes en general no perciben la repercusión que supone su proceso de regresión. Al fin y al cabo, según resumía textualmente uno de ellos, la destrucción de la Posidonia "como no se ve, no es un problema». Los autores de este estudio consideran que "cuanto mayor es el nivel de conocimiento de la sociedad acerca de Posidonia oceanica, mayor es la valoración que se le da a la importancia de la praderas sobre el litoral y los beneficios que genera» (Life Posidonia Andalucía, 2014, 75). Por este motivo, es lógico pensar que si los usuarios de la navegación de recreo supieran de antemano que la destrucción de las praderas supondría un aumento de la turbidez del agua y la degradación de su calidad, entre otros perjuicios, una parte de ellos quizás echaría el ancla allí donde no haya.

\subsection{Los impactos del anclaje en las praderas de Posidonia oceanica}

Los daños causados por la acción mecánica del anclaje están corroborados por numerosas investigaciones. Tras finalizar un trabajo de campo en la playa de El Portet en Moraira (Teulada), muy cerca del área objeto de este estudio, un equipo de investigadores hacía hincapié que las zonas "más afectadas» coincidían con las áreas de mayor afluencia de las embarcaciones recreativas (Valero et al., 2009, 29). Otra investigación llevada a cabo también en Moraira y en la isla de Tabarca (Alicante) aporta conclusiones muy similares, incidiendo en que el anclaje produce una pérdida de densidad y cobertura de las praderas, así como un aumento de la mata muerta (Pérez-Tonda et al., 2011). Un estudio ambiental sobre la fuerte presión antrópica que afecta a las praderas de Posidonia en la zona norte de Formentera, que fueron declaradas Patrimonio de la Humanidad por la Unesco a finales del siglo pasado, pone en evidencia que el fondeo de las embarcaciones había provocado en tan sólo 4 años una reducción "drástica» del $20 \%$ de su superficie (Ocean Snell, 2012). El informe técnico, elaborado sobre tres distintas áreas de estudios, recomendaba a las autoridades competentes a tomar medidas "urgentes y eficaces» con el fin de conciliar la náutica de recreo con la conservación de este ecosistema (García, 2013). En la actualidad, el fondeo entre Punta Pedrera y el Parque Natural de Ses Salines está parcialmente regulado mediante un sistema organizado de amarres, con el fin de reducir las operaciones de anclaje en algunas de las zonas de mayor concentración, como en Caló de s'Oli y las inmediaciones de la playa s'Alga. La Consejería de Medio Ambiente del Gobierno Balear instaló en 2017 numerosas boyas de uso público para embarcaciones de diferentes tamaños también en algunas áreas del litoral de Mallorca y Menorca.

Pero en el caso de Formentera, estas medidas no solucionan el problema (Ferrer, ${ }^{2017}$ ). El fondeo se ha generalizado y hecho masivo prácticamente a lo largo de toda la isla. Por este motivo, y ante la "gravedad» de la situación, el Consell de Formentera ha optado por presentar ante el Gobierno Balear un proyecto «integral» de control de fondeo para todo el litoral de la isla, ya que en el pasado, "cada vez que se ha ido a controlar una área en concreto", las embarcaciones se habían desplazado a otra zona de la costa (Ferrer, $\left.{ }^{2017}\right)$. El nuevo proyecto se basa en dos ejes fundamentales. El primero consiste en el posicionamiento de toda una serie de boyas ecológicas de amarres para las embarcaciones de medianas y grandes dimensiones, que al fin y cabo, son las que provocan el mayor impacto ambiental. El segundo consiste en 
disponer un servicio adicional para el vaciado de las sentinas o la recogida de residuos en varios puntos de la costa, lo que significaría reducir las repercusiones asociadas a la visita de las embarcaciones de recreo. En opinión de Sandra Benbeniste, directora de la Fundación para la Conservación de Ibiza y Formentera, la solución del problema podría llegar a raíz de la aprobación del Proyecto de Decreto sobre la conservación de la Posidonia en las Islas Baleares (Benbeniste S., comunicación personal, 27 de octubre de 2017). La disposición autonómica, que a día de hoy está siendo debatida en el Parlamento de las Islas Baleares, reconoce y establece por primera vez la prohibición de fondear sobre las praderas que se encuentran fuera de las áreas protegidas. A falta de su aprobación definitiva, el decreto otorgaría a las autoridades competentes el poder sancionador en caso de incumplimiento.

A la hora de fondear, un ancla causa básicamente tres tipos de impactos en las praderas, además de los daños a otras especies marinas (San Félix, 2000). El primero es el efecto directo de la caída del ancla. Ésta provoca la ruptura de los rizomas no sólo de las plantas que reciben el impacto, sino de aquellas que serán arrastradas antes de que se estabilice el anclaje. Durante la estancia de las embarcaciones, se genera el segundo impacto debido al garreo de las anclas. Al arrastre de las plantas causado por el movimiento de las anclas, se suma el efecto del movimiento de las cadenas o cuerdas. El tercer y último impacto procede de la acción ascendente o retirada del ancla. Las afecciones a las praderas de Posidonia causadas por la acción mecánica del anclaje dependen, a la vez, de varios factores, como las condiciones meteorológicas (los impactos serán mayores en caso de viento y oleaje que con el mar en calma); las dimensiones de las embarcaciones (cuanto más grande, mayor será el impacto); la técnica utilizada a la hora de izar el ancla (el impacto será mucho mayor cuando la retirada del ancla no se produce en línea vertical); la frecuencia e intensidad de los fondeos (Montefalcone et al., 2013).

Otros estudios también destacan que la magnitud de los perjuicios difiere «notablemente» según el modelo de ancla. Durante un trabajo de campo realizado en el AMP de la isla de Ustica (Norte de Sicilia), se hicieron numerosas pruebas monitorizadas con los tres tipos de anclas más utilizadas por las embarcaciones de pequeñas dimensiones locales (Milazzo et al., 2004, 56). Los autores de este trabajo consideran que el modelo de ancla puede ser "determinante» de cara a los perjuicios en las praderas de Posidonia, ya que las anclas de tipo Hall tienen un impacto menor con respecto a las anclas Danforth y Folding grapnel y (figura 4). Éstas últimas, lamentablemente, son muy habituales también entre las pequeñas embarcaciones del litoral de la Com. Valenciana (Valero et al., 2009, 36). Las anclas Folding grapnel, también conocidas como anclas de tipo rezón, tienen la ventaja de ser relativamente económicas y además ocupan poco espacio a bordo, ya que pueden cerrarse como si se tratara de un paraguas (Pascual X., Presidente del Institut de Recerca Oceanogràfica de Xàbia, comunicación personal, 26 de octubre de 2017). 
Figura 4. Principales modelos de anclas utilizadas por las pequeñas embarcaciones

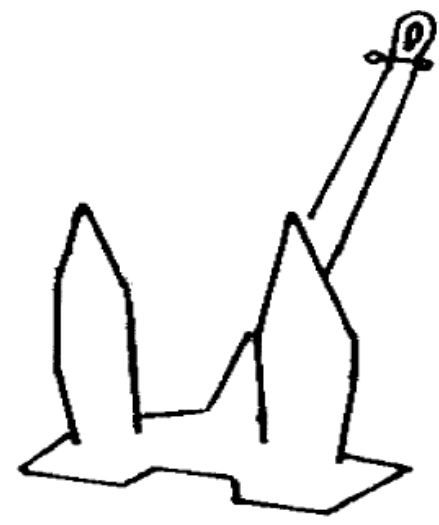

Hall

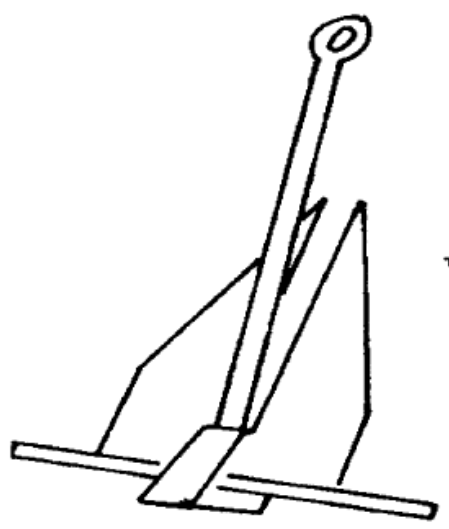

Danforth

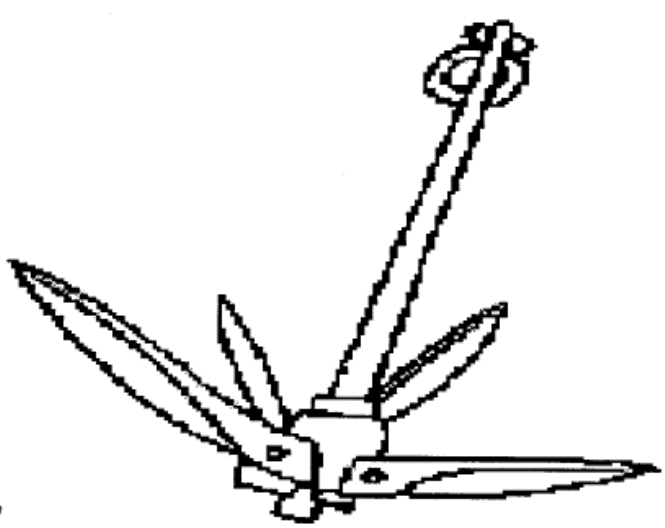

Folding grapnel

Fuente: Milazzo et al., 2004, 55

\section{EL CASO ESTUDIO DEL MUNICIPIO DE JÁVEA}

El municipio costero de Jávea, perteneciente a la comarca alicantina de la Marina Alta, ocupa una superficie de poco más de $68 \mathrm{~km}^{2}$. Su franja litoral de alrededor de $25 \mathrm{Km}$. se caracteriza por el predominio de acantilados altos y promontorios rocosos, que se hacen especialmente evidentes en la zona sur, entre Cap de Sant Martí y Morro Castell (figura 5). Este tramo costero, al que se le denomina con el nombre genérico de promontorios de La Nau, y que coincide con la vertiente más oriental del País Valenciano, está integrado por toda una serie de cabos y puntas separadas entre sí por numerosas ensenadas, calas o pequeñas playas de gravas (Vera, 1987, 43). Toda la franja costera de Jávea abarca praderas de Posidonia oceanica con una densidad "muy elevada», aunque a menudo con "escasa» cobertura a causa del predominio de los substratos rocosos (Ruiz et al., 2015, 233-234). Las principales superficies se encuentran, en efecto, en el litoral norte, es decir, en el interior de las bahías de Jávea y del Portitxol, entre Cap de Sant Antoni y Cap de Sant Martí (figura 5). 
Figura 5. Mapa de localización del área de estudio

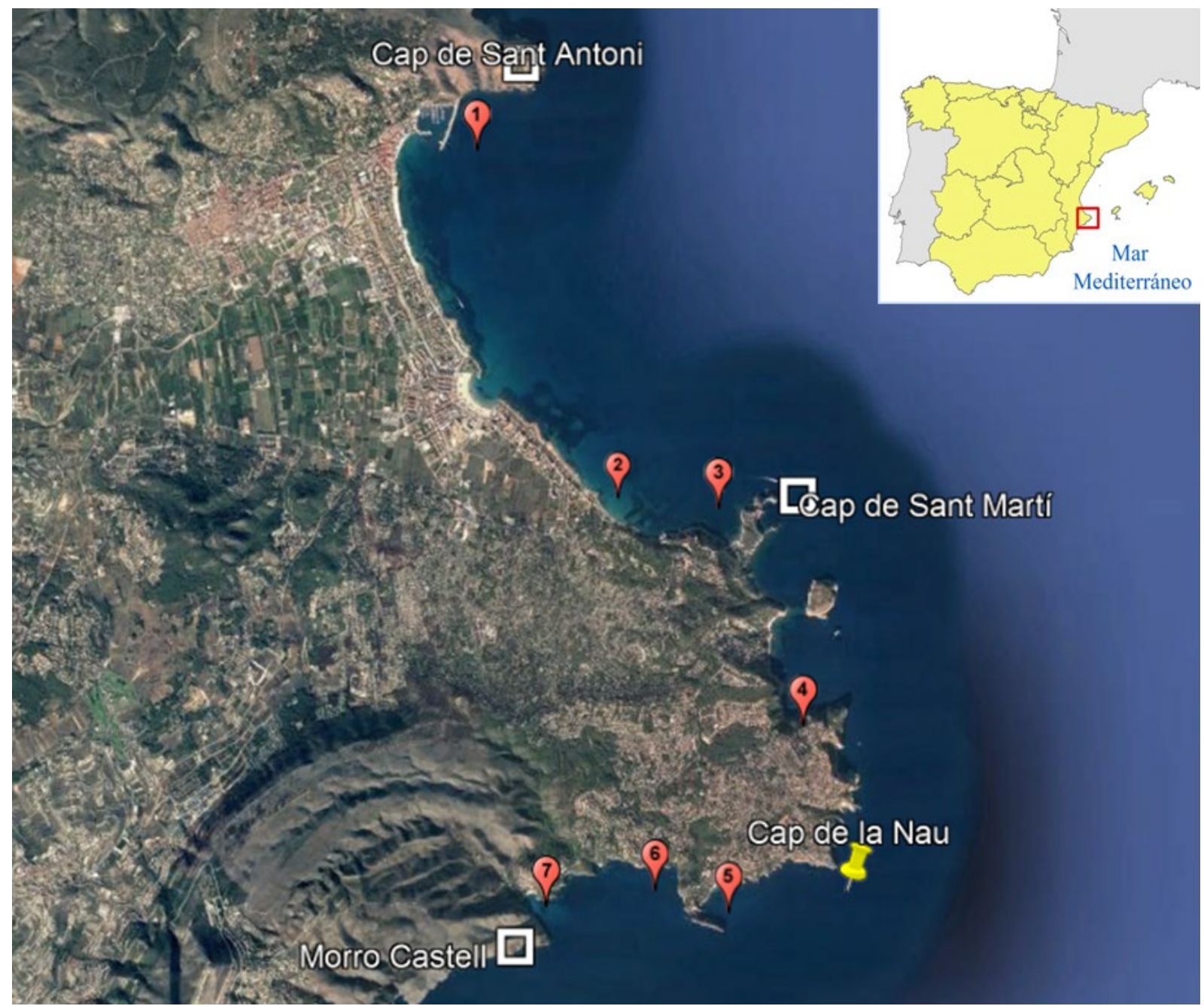

1) Cala Tangó; 2) Cala Blanca; 3) Cala Sardinera; 4) Cala Barraca; 5) Cala Ambolo; 6) En Caló;

7) Cala de la Granadella

Fuente: elaboración propia mediante Google Earth

A razón de su especial morfología, toda el área representa un lugar privilegiado para la náutica de recreo. Sea cual sea la dirección de los vientos, siempre hay zonas que están al abrigo (Baldassari G., Bolufer J., Noguera D., Carrasco L., comunicaciones personales, 27-28 de octubre de 2017). Por ejemplo, si hay vientos de levante, que suelen ser los dominantes en verano, quedan muy resguardas la Cala de la Granadella, la Cala Sardinera y En Caló, entre otros parajes (figura 5). Si los vientos son de dirección norte, prácticamente todas las calas y ensenadas al sur de Cap de la Nau, incluyendo Cala Ambolo, están al abrigo. La misma situación se produce en la Cala Tangó, que se sitúa a la izquierda de la escollera norte del puerto de Jávea. Por el contrario, si hay vientos de sur, la Cala Blanca y Cala Sardinera se convierten en los parajes ideales para fondear. De cara a la navegación de recreo, por lo tanto, gran parte de la franja costera de esta área de estudio tiene en su propia morfología uno de sus principales atractivos, además de su belleza paisajística y riqueza de los fondos. 
De acuerdo con las observaciones de campo que se han realizado, los testimonios locales y la información proporcionada por el propio Ayuntamiento de Jávea, el tráfico de embarcaciones ha alcanzado niveles muy preocupantes de masificación en la Cala Sardinera. El domingo 30 de julio de 2017, por ejemplo, en el intervalo de mayor afluencia en proximidad de la Cala Sardinera (entre las 14 y las 16 horas), se detectó el fondeo simultáneo máximo de más de 90 embarcaciones, lo que indica que el número total de operaciones de fondeo a lo largo del día fue mucho mayor. Y aunque la mayoría de los barcos eran de pequeñas dimensiones (inferiores a los 8 metros de eslora), se observó la presencia de algunos yates de más de $16 \mathrm{~m}$. de eslora. Escenarios similares se han reproducido todos los fines de semana de agosto, con variaciones poco significativas en número de operaciones. Pero la práctica del fondeo en el litoral de Jávea ha crecido de forma sostenida en los últimos años también en Cala Tangó, En Caló, Cala Blanca y Cala Barraca, así como en las inmediaciones de la Cala de la Granadella. La mayoría de las embarcaciones proceden de las dos instalaciones náutico-deportivas situadas en el propio término municipal de Jávea, el Puerto deportivo y pesquero y la Marina Fontana; buena parte del resto suele zarpar de las instalaciones cercanas de Denia y Teulada, donde la oferta de amarres de uso deportivo y de recreo ha aumentado considerablemente en las dos últimas décadas (Baldassari, Bolufer, Carrasco, 27-28 de octubre de 2017). En la actualidad, los tres municipios costeros de la comarca de la Marina Alta (Denia, Jávea y Teulada) suman poco menos de 3 mil plazas, esto es, más del doble de la oferta en 2003 (tabla 2).

Tabla 2. Instalaciones Náutico-Deportivas en los municipios de Jávea, Denia y Teulada Números de amarres de uso deportivo y de recreo (2018)

\begin{tabular}{|l|l|c|c|}
\hline \multicolumn{1}{|c|}{ Municipio } & \multicolumn{1}{|c|}{ Instalación } & Amarres & Eslora máxima (m.) \\
\hline \multirow{4}{*}{ Jávea } & Marina Fontana & 488 & 8 \\
\cline { 2 - 4 } & $\begin{array}{l}\text { Puerto deportivo y } \\
\text { pesquero }\end{array}$ & 380 & 16 \\
\hline \multirow{5}{*}{ Denia } & Marina de Denia & 450 & 60 \\
\cline { 2 - 4 } & Marina El Portet & 424 & 30 \\
\cline { 2 - 4 } & Real Club Náutico & 601 & 20 \\
\hline \multirow{2}{*}{ Teulada } & $\begin{array}{l}\text { Puerto deportivo de } \\
\text { Moraira }\end{array}$ & 620 & 25 \\
\hline & & $\mathbf{2 . 9 6 3}$ & $====$ \\
\hline
\end{tabular}

Fuente: elaboración sobre datos facilitados por las respectivas instalaciones

Ante la proliferación de la navegación de recreo, el Ayuntamiento de Jávea ha optado por incrementar las medidas de protección de la propia área costera. De acuerdo con el nuevo Proyecto de construcción y mantenimiento: instalaciones de balizamiento y plataformas lúdicas en el litoral de Jávea (2017-2021), que fue elaborado por la empresa Consultores de Infraestructuras y Medioambiente CIMA S.L., se establecieron durante la temporada veraniega de 2017 nuevos puntos de fondeo regulado en las áreas de mayor concentración. El sistema consiste básicamente en la colocación de una serie de boyas de amarres para las embarcaciones de recreo. Esta medida se suma a las acciones de balizamientos de playas, canales de navegación, instalación de plataformas lúdicas y posicionamiento de boyas para señalizar la 
presencia de buceadores. La figura 6 muestra la distribución final de los puntos de fondeo regulado, con indicación del número de boyas de amarre por cada una de las zonas de actuación.

Figura 6. Distribución de los puntos de fondeo regulado en el litoral de Jávea (2017)

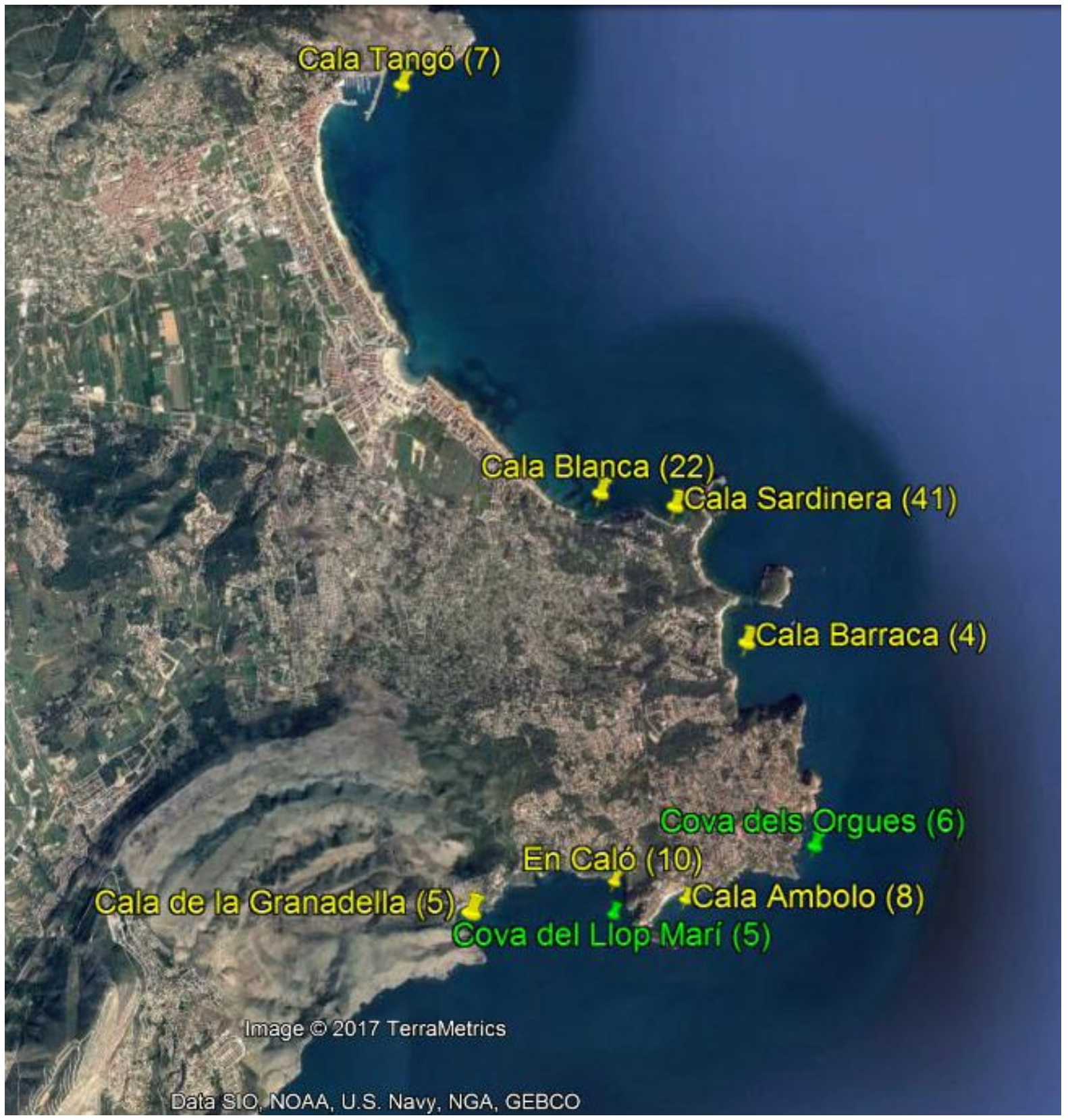

*Entre paréntesis el número de boyas de amarre para embarcaciones de recreo

Fuente: elaboración propia mediante Google Earth sobre datos de CIMA S.L. (2016) y observaciones de campo

La solución adoptada por el Ayuntamiento de Jávea, que reproduce una estrategia ya implementada en otros destinos costeros del Mediterráneo, supone un indudable beneficio 
ambiental. Las boyas de amarre evitan el anclaje, lo que reduce la presión y el impacto en los fondos marinos. Esta medida de gestión, además, suele ser bien recibida por los navegantes. "Los patrones de embarcaciones somos los primeros en respaldarla. A paridad de condiciones de ubicación, preferimos amarrar a una boya en lugar de echar el ancla» (Estalrich F., comunicación personal, 27 de octubre de 2017). Las operaciones de fondeo no regulado pueden de hecho suponer varios inconvenientes. Por ejemplo, el ancla puede enredarse con la cuerda o cadena de otra embarcación, así como quedarse enganchada en el fondo, a veces de manera definitiva, sobre todo cuando se trata de un fondo rocoso como en el caso del litoral de Jávea.

La buena aceptación social de los fondeos regulados ha favorecido su difusión y desarrollo. En el AMP de las Islas Égadas, en Sicilia, se organizaron 14 campi ormeggio (áreas de amarres) en 2017, por un total de más de 150 boyas. "Desde que optamos por la regulación de los fondeos» en 2010, la respuesta de los navegantes ha sido «muy favorable», hasta tal punto que «hemos resuelto establecer finalmente un sistema de reserva de pago mediante una aplicación informática» (Laporta P., comunicación personal, 26 de octubre de 2017). Los ingresos procedentes permiten rentabilizar las inversiones, lo cual asegura su sostenibilidad económica. El directivo de la AMP de las Islas Égadas, una de las reservas marinas más extensas del Mediterráneo (54 mil ha.), considera que la puesta en marcha de un área de amarre debe ser «siempre» acompañada por una labor de información sobre los beneficios ambientales que ello supone:

resulta muy importante llevar a cabo, y con cierta frecuencia, una campaña de sensibilización sobre los perjuicios asociados a los malos hábitos. Lamentablemente, no todos los navegantes se caracterizan por una adecuada conciencia ecológica.

Pero la puesta en marcha de un área de amarres no siempre es sinónimo de beneficios ambientales. Hay dos aspectos estructurales que resultan finalmente clave. El primero consiste en colocar una boya de profundidad o boya intermedia entre el elemento de sujeción en el fondo y la boya de superficie. Esta boya auxiliar, según se observa en la figura 7, impide que la cadena se arrastre y deteriore los fondos marinos. El segundo aspecto se refiere a la fijación de la boya en el terreno. Cuando empezaron a instituirse las primeras áreas de amarre, durante los años 1970, las boyas tenían su única herramienta de sujeción en una base de hormigón (figura 8), fuera cual fuera el tipo de fondo sobre el que se iba a colocar: arenoso o duro (rocoso). Algunos estudios, no obstante, muy pronto detectaron que el llamado 'muerto de hormigón' provocaba un grave impacto en los fondos con presencia de fanerógamas u otros ecosistemas (Robert, 1983). Varios investigadores se plantearon de hecho la duda de si el remedio finalmente no era casi peor que la enfermedad (Boudouresque et al., 2008, 87). Al perjuicio que supone una base de hormigón encima de las praderas, se suma el movimiento y el consiguiente arrastre de las cadenas de sujeción, debido a las corrientes y el oleaje. 
Figura 7. Modelo de boya auxiliar de profundidad o boya intermedia
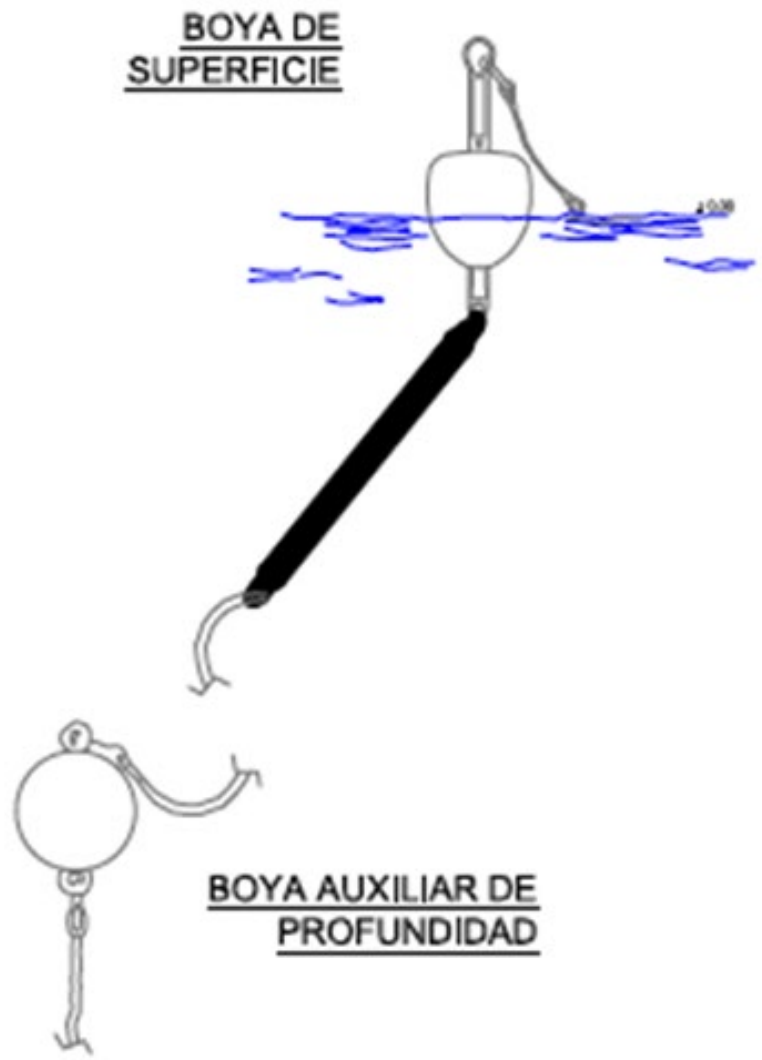

Fuente: http://danielaguilo.com/fondeos-ecologicos (último acceso 30 de junio de 2018)

Figura 8. Modelo de base de hormigón de sujeción de las boyas

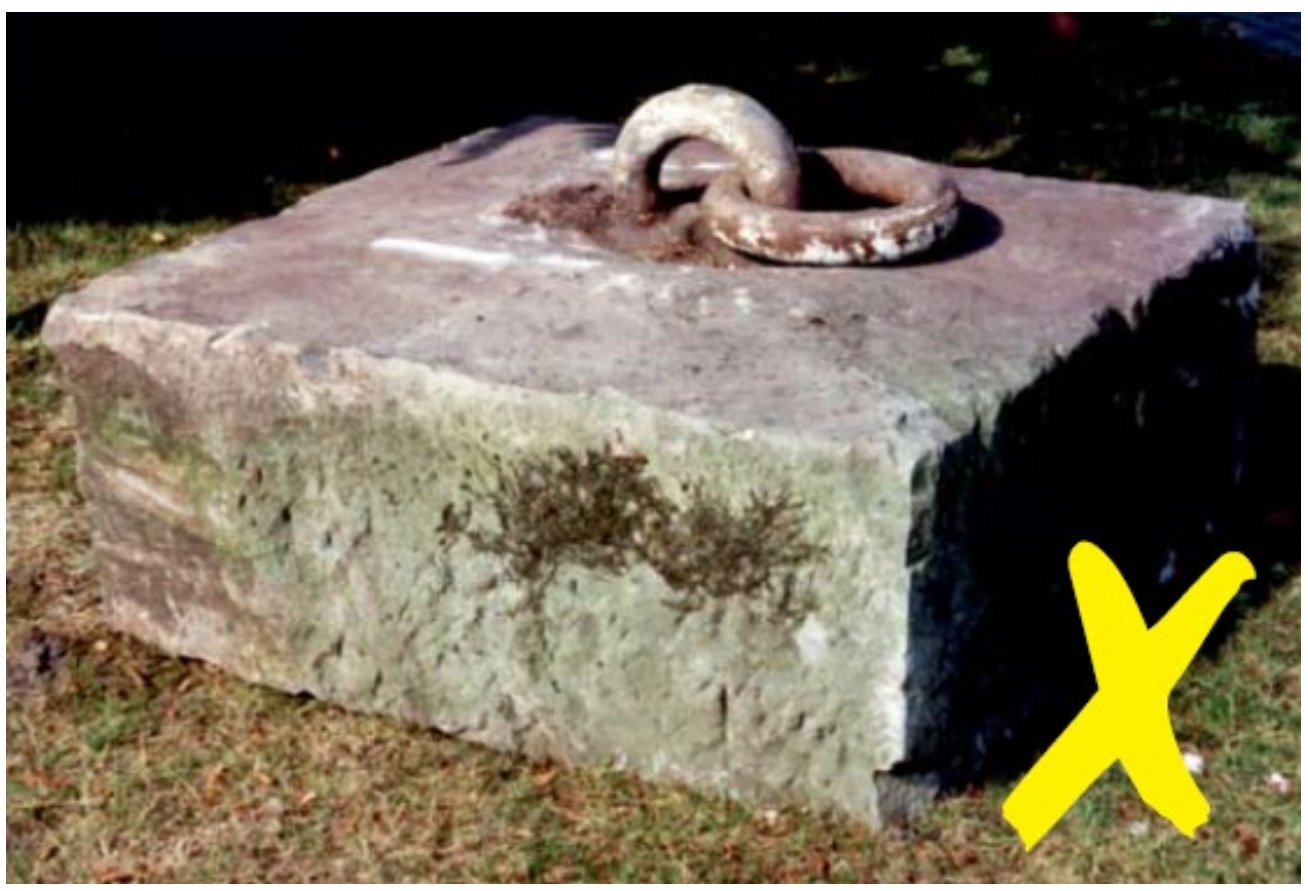

Fuente: archivo personal de Laporta P., directivo de la AMP de las Islas Égadas 
Por este motivo, desde finales del siglo pasado, se han ido implantando varios sistemas de sujeción de las boyas que minimizan los impactos ambientales. Hoy en día el mercado ofrece diferentes modelos de anclajes ecológicos adaptables a todo tipo de terreno. Uno de los sistemas más difusos, ya que fue el primero en desarrollarse, se conoce como el anclaje Armony. Se compone de un muelle helicoidal que se inserta en el terreno, a la vez que su extremo superior se une a la boya auxiliar de profundidad mediante una driza (figura 9). En 2006, se instalaron más de 400 unidades de este tipo de anclaje en varias zonas del litoral de las Baleares, en el marco del Proyecto Life Posidonia promovido por la Consejería de Medio Ambiente del gobierno balear (García, 2013, 15).

Este sistema, que es adecuado para los fondos arenosos, tiene múltiples variantes. La principal sino única diferencia estriba en la pieza enterrada. Gracias a la evolución tecnológica, se han desarrollado instrumentos más fáciles de insertar y más resistentes a la corrosión. Para los fondos duros, se suelen utilizar unos tacos químicos consistentes en un perno de anclaje cimentado con resina u otra sustancia insoluble. En resumen, sea cual sea el modelo elegido, su empresa productora o el tipo de terreno, los anclajes ecológicos ofrecen muchas ventajas con respecto al sistema clásico del muerto de hormigón, incluso desde la perspectiva económica. El mayor coste de inversión se compensa a muy corto plazo con el ahorro asociado a su mantenimiento.

Figura 9. Modelo de boya ecológica con anclaje Armony

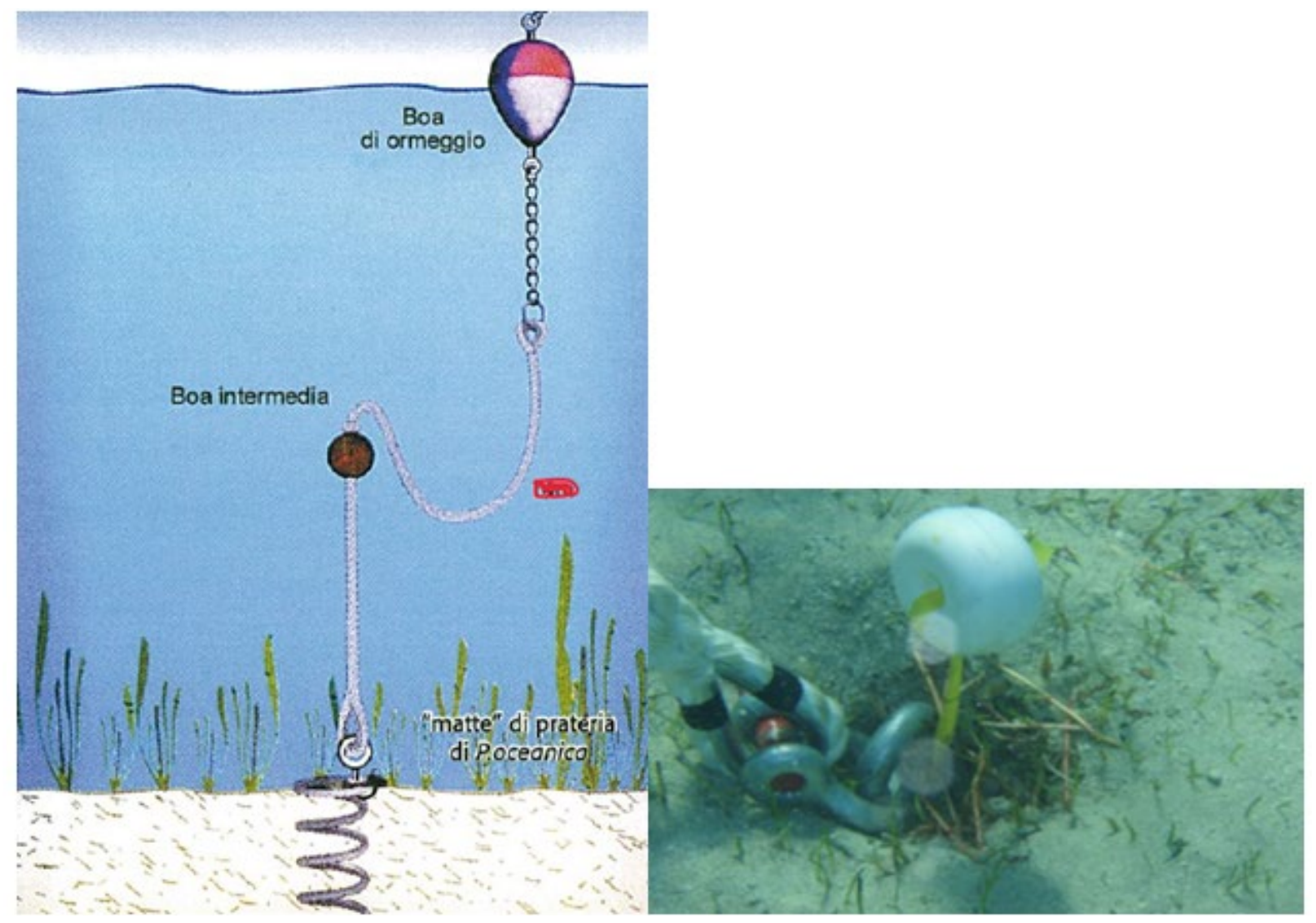

Fuente: Boudouresque et al., 2008, 88; http://danielaguilo.com/fondeos-ecologicos (último acceso 30 de junio de 2018) 
El plan de gestión emprendido por el Ayuntamiento de Jávea plantea dos tipos de sujeción de boyas de amarre, en función de la tipología del fondo. Ambos sistemas se resumen en la figura 10. En los fondos donde no existen praderas, la empresa consultora se inclina por el sistema clásico de sujeción, haciendo hincapié en que «el uso de los muertos de hormigón se limitar[í]a a fondos blandos sin presencia de flora» (CIMA S.L., 2016, 333). Básicamente se plantea el uso de 4 tipos de muertos de hormigón en función del peso, entre un mínimo de $125 \mathrm{Kg}$. hasta un máximo de $1.500 \mathrm{Kg}$. Los primeros se retiran una vez terminada la temporada estival, mientras que los más grandes $(500,800$ y $1.500 \mathrm{Kg}$.) permanecen en el fondo indefinidamente para ser utilizados en los años siguientes.

Figura 10. Modelos de boyas ecológicas en el litoral de Jávea

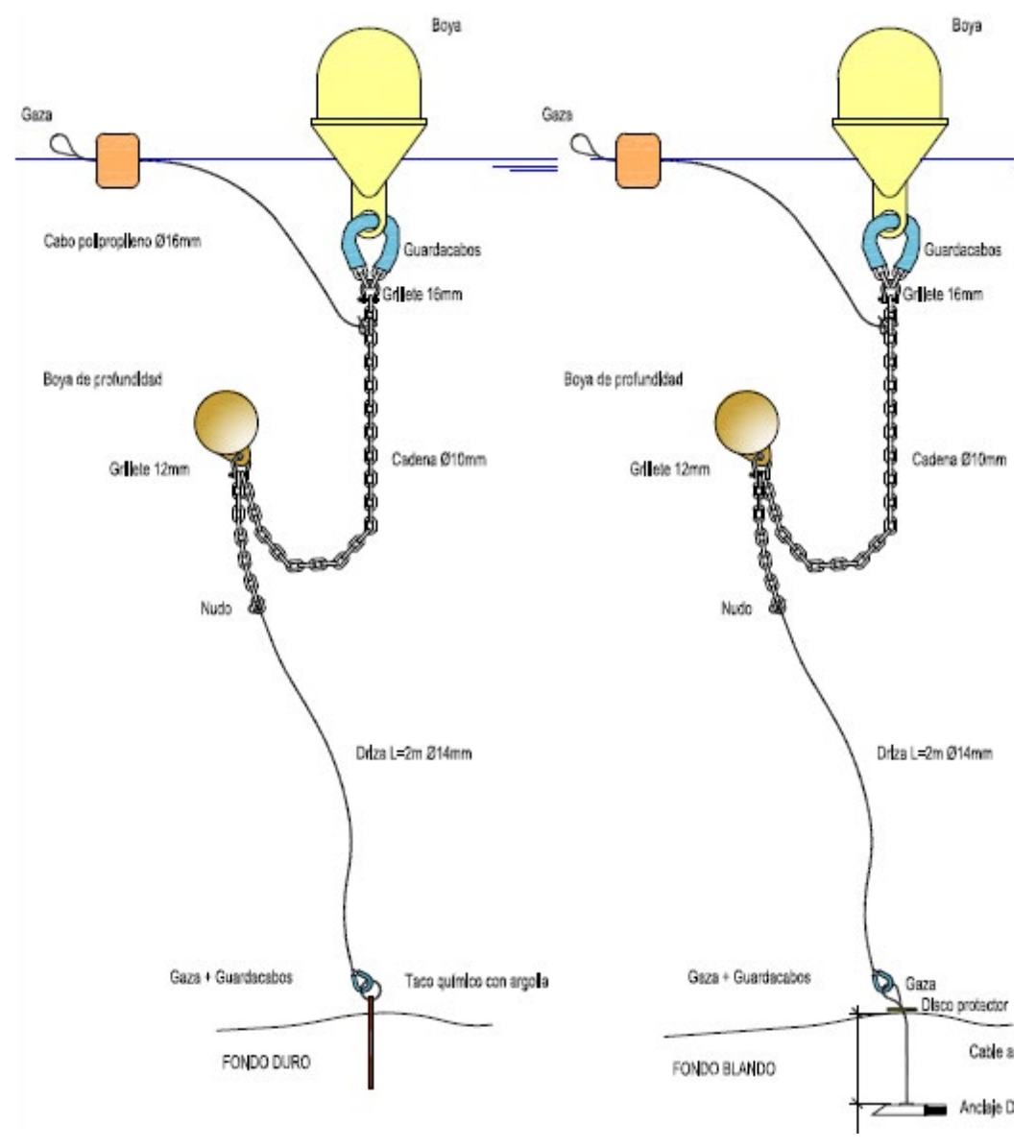

Fuente: CIMA S.L. (2016)

Durante el trabajo de campo, se han detectado otros inconvenientes acerca de la disposición de las boyas. Básicamente se han divisado tres tipos de anomalías: boyas sujetas a muertos de hormigón en los fondos con presencia de Posidonia oceanica; muertos de hormigón arrastrados por corrientes y tormentas; ausencia de boyas intermedias, con el consiguiente arrastre de la cadena (figura 11). Este diagnóstico coincide con la información del IROX, el Institut de Recerca Oceanogràfica de Xàbia-Jávea, que por otra parte ya había denunciado estos inconvenientes en 2016 (Pascual X., 28 de octubre de 2017). 
Además, la oferta de boyas de amarres se demostró muy inferior a la demanda real. Mediante observaciones puntuales, este escenario pudo apreciarse a lo largo de todas las zonas de actuación. A todos los efectos, se hizo evidente que la cantidad de boyas se había quedado corta. Durante muchos fines de semana, el número diario de embarcaciones llegó a triplicar el número de boyas en varios parajes del litoral de Jávea, como el caso de la Granadella. El tráfico de embarcaciones, por otra parte, fue elevado también en la segunda quincena de octubre, es decir, después de que las boyas habían sido retiradas por la empresa concesionaria, de acuerdo con lo establecido por el contrato con el Ayuntamiento. El domingo 22 de octubre, de hecho, había casi más embarcaciones en proximidad de En Caló que un domingo de verano (Baldassari G., 28 de octubre de 2017).

Figura 11. Anomalías detectadas en algunas boyas del litoral de Jávea (2016-2017)

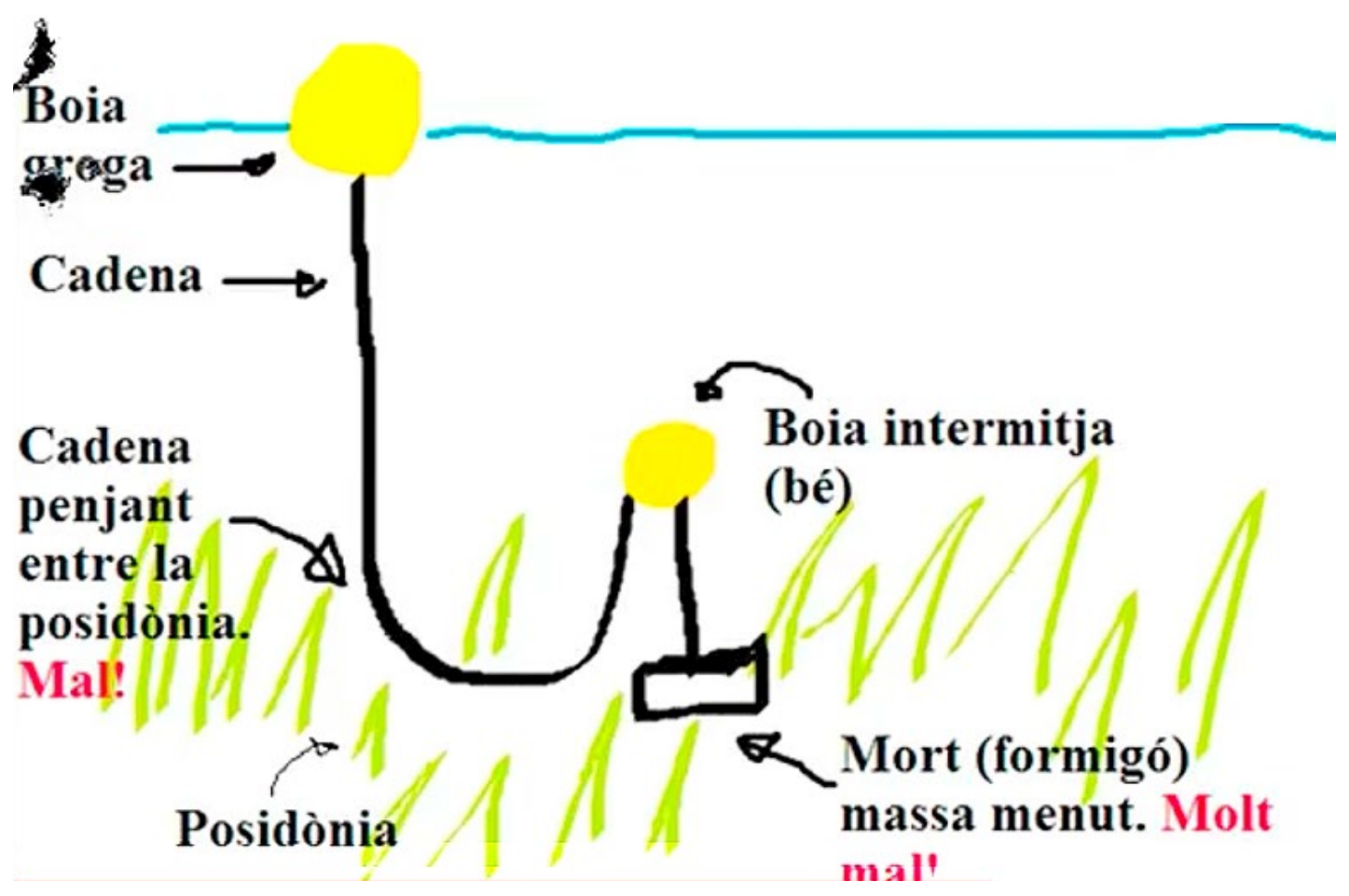

Fuente: http://irox.cat/ (último acceso, 30 de junio de 2018)

\section{CONCLUSIONES}

La náutica de recreo tiene importantes beneficios económicos y genera mucho empleo. Además, junto al resto de las modalidades recreativas asociadas al disfrute activo del mar, favorece la desestacionalización de la actividad turística. Todo ello adquiere una mayor trascendencia en el área de estudio de la presente investigación, donde el turismo náutico se ha convertido en una realidad muy difusa e integrada. Pero las instalaciones náutico-deportivas y la consecuente oferta de amarres conllevan también una fuerte presión en la zona marítima adyacente. El fondeo masivo en proximidad de la costa se ha generalizado. Las embarcaciones 
anclan en las inmediaciones de playas, calas y cualquier otro espacio que queda al abrigo de los vientos. El tráfico de embarcaciones ha alcanzado niveles muy preocupantes de saturación.

A partir de los argumentos que se han comentado en las páginas anteriores, se considera necesaria la aplicación de las siguientes actuaciones de ámbito local, con el fin de conciliar la conservación del medio ambiente con los beneficios económicos y sociales de la náutica de recreo. Las recomendaciones se dirigen principalmente a las administraciones locales, que son quienes deben liderar una política eficaz de gestión sostenible de sus recursos naturales. Las actuaciones de ámbito local se consideran determinantes para la preservación de las praderas marinas (Guillén et al., 2013). A falta de una legislación que prohíba y sancione el fondeo sobre las praderas en las áreas no protegidas, y debido a la selva competencial que atañe a cualquier actuación en el ámbito marítimo-terrestre, no hay otro camino que adoptar medidas eficaces de regulación. A día de hoy, resulta imposible solucionar definitivamente este problema. Cabe reiterar que la protección de las praderas de Posidonia no tiene una justificación estrictamente ambiental. La Posidonia aporta un valor económico directo a la pesca y al turismo, entre otros sectores. Su desaparición a nivel local tendría un efecto nefasto en la economía de los destinos litorales.

A. Promover un trabajo de cartografía detallada de los fondos marinos para poder disponer de una información sobre el estado de la Posidonia u otras fanerógamas presentes en el propio litoral. Antes de cualquier toma de decisiones, se hace imprescindible tener un conocimiento riguroso y actualizado de cuál es el estado de las praderas. Este tipo de proyecto se está llevado a cabo en Formentera, bajo la dirección del biólogo Manu San Félix. La labor de cartografía deberá también servir para dar seguimiento a la evolución de las praderas.

B. Poner en marcha un sistema efectivo de control y seguimiento de los fondeos. Esta actuación se justifica por la necesidad de obtener la mayor información posible, cuantitativa y cualitativa, sobre el tráfico de embarcaciones de recreo por el propio litoral. En las zonas de mayor concentración de Portofino, por ejemplo, se han instalado varias cámaras de vigilancia, lo que se suma a la labor de recopilación que se efectúa desde pequeñas lanchas motoras. Este sistema de seguimiento permite conocer la cuantía de los fondeos, su duración, períodos de mayor y menor afluencia, tipología de embarcaciones y todo tipo de datos relacionados con esta modalidad recreativa. Se trata de tener una visión global y detallada de la actividad de los fondeos.

C. En toda área en la que coinciden dos condiciones, esto es, concentración masiva de embarcaciones y presencia de praderas, habrá que establecer una reglamentación de los fondeos con el fin de reducir la presión que ejercen las operaciones de anclaje. La creación de los puntos de fondeos regulados deberá llevarse a cabo sobre la base de los datos obtenidos por medio de las actuaciones $\mathrm{A}$ y $\mathrm{B}$. El número de boyas de amarres, por lo tanto, deberá estar relacionado con el número de fondeos que se han detectado, así como la distancia entre éstas deberá calcularse en base a la tipología de las embarcaciones. Para ello habrá que tener presente el 
radio de borneo ${ }^{2}$ y añadir un margen de seguridad para evitar la rozadura entre las embarcaciones contiguas.

D. Las áreas organizadas de amarre deberán disponer única y exclusivamente de boyas ecológicas. Se desaconseja el uso de los muertos de hormigón como elemento de sujeción, sea cual sea el tipo de fondo. Al mismo tiempo, toda boya de superficie deberá tener su boya de profundidad para evitar que la cadena se arrastre por el fondo.

E. Para su efectividad, los puntos organizados de fondeo implican la puesta en marcha de los mecanismos necesarios de vigilancia. La labor del personal encargado de esta tarea consiste básicamente en asegurarse que los navegantes eviten el anclaje, utilizando por ello las boyas de amarres. Cuando todas las boyas estén ocupadas, se tratará de invitarles a fondear allí donde no hay praderas.

F. Toda acción de reglamentación será eficaz siempre y cuando esté acompañada por una labor de información sobre las afecciones que causan los fondeos irresponsables y otras conductas perjudiciales. El desconocimiento generalizado sobre los beneficios de las praderas de Posidonia y la repercusión que tendría su desaparición, hacen imprescindible llevar a cabo campañas formativas y de concienciación. Cabe reiterar que los malos hábitos son los responsables de buena parte de las afecciones ambientales asociadas a la práctica del fondeo. Las labores de información y concienciación deberían llevarse a cabo en colaboración con los puertos deportivos locales y las empresas de chárter náutico.

\section{REFERENCIAS BIBLIOGRÁFICAS}

Adame J. (2009). Impacto económico de los puertos deportivos. Congreso de Turismo Náutico de Barcelona, 11 de noviembre de 2009. Recuperado de http://www.anen.es

Alcover A., Alemany M., Jacob M., Payeras M. y García A. (2011). The economic impact of yacht charter Tourism on the Balearic economy. Tourism Economic, 18(3), 625-638.

ANEN (2012). Impacto económico de la náutica de recreo en España y propuestas para su crecimiento. Resumen Ejecutivo, abril de 2012. Recuperado de http://www.anen.es

ANEN (2014). Nota de Prensa del 9 de enero de 2014. Recuperado de http://www.anen.es

Antón S. (2004). De los procesos de diversificación y cualificación a los productos turísticos emergentes. Cambios y oportunidades en la dinámica reciente del turismo litoral. Papeles de Economía Española, 102, 316-333.

Besteiro B. (2004). El desarrollo del turismo náutico en Galicia. Cuadernos de Turismo, 13, 145-163.

Boletín Oficial de la Provincia de Alicante, 120, 26 de junio de 2017.

Boletín Oficial del Estado, 79, 2 de abril de 1966.

Boudouresque C.F., Bernard G., Bonhomme P., Charbonnel E., Diviacco G., Meinesz A., Pergent G., Pergent-Martini C., Ruitton S., Tunesi L. (2008). Tutela e conservazione delle praterie di Posidonia oceanica. Ed. Ramoge. Recuperado de http://www.ramoge.org

2. El borneo es el movimiento circular que describe una embarcación alrededor de la posición de fondeo. 
Burgin S. y Hardiman N. (2011). The direct physical, chemical and biotic impacts on Australian coastal waters due to recreational boating. Biodiversity and Conservation, 20(4), 683-701.

Cabrera B. (2011). El sector náutico en Las Palmas de Gran Canaria. Análisis y propuestas. Las Palmas de Gran Canaria: FEMEPA.

Cappanera V., Bava S., Venturini S., Cattaneo-Vietti R., Povero P. (2008). Valutazione dell'impatto antropico sul sistema costiero, con particolare riferimento alla pressione antropica all'interno dell'Area Marina Protetta del Promontorio di Portofino. AMP di Portofino y Università di Genova. Recuperado de http://www.portofinoamp.it

Celdrán M.A. (2016) El producto náutico-deportivo como elemento dinamizador del turismo litoral. Canelobre, 66, 335-342.

CIMA S.L. Consultores de Infraestructuras y Medioambiente (2016): Proyecto de construcción y mantenimiento: instalaciones de balizamiento y plataformas lúdicas en el litoral de Jávea (2017-2021). Informe concedido por el Ayuntamiento de Jávea.

Clark C., Pakhomov E.A y Therriault T.W (2011). Recreational boating: a large unregulated vector transporting marine invasive species. Diversity and distribution, 17(6), 1161-1172.

CLIA Europe. Annual Report. Contribution of cruise tourism to the economies of Europe, 2015. Recuperado de https://www.cliaeurope.eu/

Contini M.V. (2010). Nautica da diporto e portualitá come elementi di qualificazione del turismo náutico nelle aree marine protette: il caso dell' A.M.P. di Tavolara - Punta Conta Cavalli (PhD. dissertation). Università di Sassari.

Dafforn K.A., Glasby T.M., Johnson E.L. (2008). Differentiel effects of tributyl tin and copper antifoulants on recruitment of non-indigenous species, Biofouling, 24, 23-33.

Donato C. y Battino S. (2009). II peso del turismo che non appare e la pressione turistica sugli ambiti di paesaggio costieri del Nord Sardegna. En Scanu G. (coord.), Paesaggi e sviluppo turistico. Sardegna ed altre realtá geográfiche a confronto. Atti di convegno di studi, Olbia 15-17 de octubre de 2008 (pp. 539-554). Roma: Carocci.

Espejo Marín C. (2011). Innovación para la competitividad turística en la Manga del Mar Menor. Cuadernos de Turismo, 27, 321-339.

Esteban V. (1998). Las instalaciones náuticas de recreo. En Esteban V. (dir.), Náutica de recreo y turismo en el Mediterráneo: La Comunidad Valenciana (pp. 13-62). Valencia: AVT.

Esteban V. (2003). La náutica como producto turístico. En Martín F.J. (dir.), Curso práctico de dirección de instalaciones náuticas de recreo (pp. 11-29). Universidad de Alicante.

Favro S., Kovačić, M., Gržetić, Z. (2008). Nautical tourism the basis of the systematic development. Scientific Journal of Maritime Research, 22, 31-51.

FEAPDT, Informe anual de puertos deportivos en España, 2007-2015. Recuperado de http:// www.feapdt.es

Ferradás S. (2001). La relevancia del turismo náutico en la oferta turística. Cuadernos de Turismo, 7, 67-80.

Ferradás S. (2002). El turismo náutico en el Mediterráneo. Cuadernos de Turismo, 9, 19-32.

Ferrer Kirschbaum A. (2017) Ponencia de la Consellera de Territori i Turisme de Formentera en el Mediterrania Jávea Forum, 26 de octubre de 2017, Recuperado de https://www. youtube.com/watch?v=5hZ3FhdBrIM 
Floerl O. (2002). Intercoastal spread of fouling organism by recreational vessels (PhD. dissertation). James Cook University (Townsville).

Fornes A., Bastrerretxea G., Orfila A., Jordi A., Alvárez A. y Tintoré J. (2006). Mapping Posidonia oceanica from IKONOS. ISPRS Journal of Photogrammetry \& Remote Sensing, 60, 315-322.

Francour P., Ganteaume A., Poulain M. (1999). Effects of boat anchoring in Posidonia oceanica seagrass beds in the Port-Cros National Park (north-western Mediterranean Sea). Aquatic Conservation: Marine and Freshwater Ecosystem, 9, 391-400.

Gacia, E., Duarte C.M. (2001). Sediment retention by a Mediterranean Posidonia oceanica meadow: the balance between deposition and resuspension. Estuarine, Coastal and Shelf Science, 52, 505-514.

Ganteaume A., Bonhomme P., Bernard G., Poulain M., Boudouresque C.F. (2005). Impact de l'ancrage des bateaux de plaisance sur la prairie à Posidonia oceanica dans le Parc national de Port-Cros (Méditerranée nord-occidentale). Sci.Rep. Port-Cros natl. Park, Fr. 21, 147-162

García C. (2013). Impactos de los fondeos de embarcaciones recreativas sobre las praderas de Posidonia Oceanica en el Parque natural de Ses Salines d'Eivissa i Formentera (TFC). Universitat de les Illes Balears.

García M. (2006). Los puertos deportivos del litoral onubense. Huelva: Universidad de Huelva.

Gera A., Alcoverro T., Mascaró O., Pérez M., Romero J. (2012). Exploring the utility of Posidonia oceanica chlorophyll fluorescence as an indicator of water quality within the European Water Framework Directive. Environ Monit Assess, 184, 3675-3686.

Gómez E. (2012). La gestión de instalaciones náuticas de recreo: su relación con el turismo náutico en la Costa Blanca. Investigaciones Turísticas, 4, 119-131.

González-Correa J.M., Bayle J.T., Sánchez-Lizaso J.L., Valle C., Sánchez-Jerez P., Ruiz J.M. (2005). Recovery of Deep Posidonia oceanica meadows degraded by trawling. Journal of Experimental Marine Biology and Ecology, 320, 65-76.

Guillén J.E., Sánchez J.L., Jiménez S., Martínez J., Codina A., Montero M., Triviño A., Soler G., Zubcoff J.J. (2013). Evolution of Posidonia oceanica seagrass meadows and its implications for management. Journal of Sea Research, 83, 65-71.

Hay C.H. (1990). The dispersal of sporophytes of Undaria pinnatifida by coastal shipping in New Zeland, and implications for further dispersal of Undaria in France. British Phycological Journal, 25, 495-499.

Heck K.L., Hays G., Orth R.J. (2003). Critical evaluation of the nursery role hypothesis for seagrass meadows. Marine Ecology Progress Series, vol. 253, 123-136.Kovačić M., Gržetić Z., Bosković D. (2011). Nautical tourism in fostering the sustainable development: a case study of Croatia's coast and island. Tourismos: an International Multisciplinary Journal of Tourism, 6(1), 221-232.

Lam-González Y.E., León C.J, Ledesma J.d.L (2017). Preferencias y valoración de los navegantes europeos en Canarias (España). Cuadernos de Turismo, 39, 311-342.

Landaluce A. (2012). Situación y futuro de la náutica de recreo en España. Propuestas dinamizadoras. Economía industrial, 386, 69-78. 
Life Posidonia Andalucía. Conservación de las praderas de Posidonia oceanica en el Mediterráneo Andaluz. Junta de Andalucía, Consejería de Agricultura, Pesca y Desarrollo Rural, 2014. Recuperado de http://www.juntadeandalucia.es/medioambiente

López y Royo C., Pergent G., Alcoverro T., Buia M.C., Casazza G., Martínez-Crego B., Pérez M., Silvestre F., Romero J. (2011). The seagrass Posidonia oceanica as indicator of coastal water quality: Experimental intercalibration of classification systems. Ecological Indicators, 11, 557-563.

Luković T. (2013). Nautical tourism. Dubrovnik: Cabi.

Lloret J., Zaragoza N., Caballero D., Riera V. (2008). Impacts of recreational boating on the marine environment of Cap de Creus (Mediterranean Sea). Ocean and Coastal Management, 51, 749-754.

Méndez G. (2007). El turismo náutico. Madrid: Turespaña.

Milazzo M., Badalamenti F., Ceccherelli G., Chemello R. (2004). Boat anchoring on Posidonia oceanica beds in a marine protected area (Italy, western Mediterranean): effect of anchor types in different anchoring stages. Journal of Experimental Marine Biology and Ecology, 299, 51-62.

Montefalcone M., Morri C., Albertelli G., Nike C. (2013). Studio metodologico sulla valutazione dello stato di conservazione dei posidonieti sottoposti a forte pressione di ancoraggi da parte delle imbarcazioni da diporto. Università di Genova. Recuperado de http://www. ramoge.org

OCEAN SNELL (2012). Evaluación del impacto del fondeo de embarcaciones sobre las praderas de Posidonia oceanica en el norte de Formentera (Baleares). Recuperado de http:// uicnmed.org/bibliotecavirtualposidonia

Padilla D.K., Chotkowski M.A. y Buchan L.A. (1996). Predicting the spread of zebra mussels (Dreissena polymorpha) to inland waters using boater movement patterns. Global Ecology and Biogeography Letters, 5, 353-359.

Panzeri S. (2008). Brevi considerazioni sull'impatto ambientale delle infrastrutture della nautiza da diporto. Giureta. Rivista di diritto dell'economia, del transporti e dell'ambiente, VI, 1-8.

Pérès J.M. (1984). La régression of des herbiers. En Boudouresque C.F., Jeudy de Grissac A., Olivier J. (eds.), International Workshops Posidonia oceanica Beds (pp. 445-454). Marsella: GIS Posidonie.

Pérez-Tonda T., Forcada A., Sánchez-Lizaso J.L. (2011). Evaluación de los efectos del anclaje de embarcaciones sobre pradera de Posidonia oceanica (L.) en dos localidades mediterráneas. Mediterranea:Serie de estudios biológicos, Época II (22), 230-250

Port de Barcelona (2014). Actividad de cruceros en Barcelona. Impacto sobre la economía catalana y perfil socioeconómico del crucerista. Recuperado de http://www.barcelona.cat

Power A.J., Walker R.L., Payne K., Hurley D (2004). First occurrence of the nonindigenous Green Mussel, Perna viridis (Linnaeus, 1758) in Coastal Georgia, United States. Journal of Shellfish Research, 23, 741-744.

Ramós A., Aranda A., Gras D., Guillén J.E. (1994). Impactos sobre las praderas de Posidonia oceanica (L.) Delile en el SE español: necesidad de establecer herramientas de ordenamiento y gestión del litoral. En Actes du colloque scientifique, Montpellier, 28-29 avril 1994. 
Robert P. (1983). Dégradation de l'herbier de Posidonies dans la zone de mouillage organisé de la baie de Port-Cros, Trav. Sci. Parc Nation, 9, 195-197.

Roca G., Romero J., Columbu S., Farina S., Pagès J.F., Gera A., Inglis G., Alcoverro T. (2014). Detecting the impacts of harbour construction on a seagrass habitat and its subsequent recovery. Ecological Indicators, 45, 9-17.

Romerto J., Martínez-Crego B., Alcoverro T., Pérez M. (2007). A multivariate index based on the seagrass Posidonia oceanica (POMI) to assess ecological status of coastal waters under the water framework directive (WFD). Marine Pollution Bulletin, 55, 196-204.

Ruiz J.M. y Romero J. (2003). Effects of disturbances caused by coastal constructions on spatial structure, growth dynamics and photosynthesis of the seagrass Posidonia oceanica. Marine Pollution Bulletin, 46, 1523-1533.

Ruiz J.M., Guillén E., Ramos A., Otero M. (2015). Atlas de las praderas marinas de España. Murcia-Alicante-Málaga: IEO/IEL/UICN.

Ruiz J.M., Marín A., Calvo J.F., Ramírez -Diaz L. (1993). Interactions between floodway and coastal constructions in Aguilas Bay (southeastern Spain). Ocean and Coastal Management, $19,241-262$.

San Félix M. (2000). La Posidonia: el bosc submergit. Palma de Mallorca: Conselleria de Medio Ambiente.

Torres F.J. (2002). Conflictos en el litoral por la construcción de puertos deportivos: el caso de Jávea (Alicante). En Fernández F., Pumares P., Asensio A. (eds.), Turismo y transformaciones urbanas en el siglo XXI (pp. 371-381). Universidad de Almería.

Valero M., Tena J., Torres J., Royo M. (2009). Estudio de la pradera de Posidonia oceanica (L.) Delile del área del litoral del municipio de Teulada (Alicante). Nereis. Estudios y propuestas científico técnicas, 2, 29-39.

Vassallo P., Paoli C., Rovere A., Montefalcone M., Morri C., Bianchi C.N. (2013). The value of the seagrass Posidonia oceanica: A natural capital assessment. Marine Pollution Bulletin, 71, 157-167.

Vera Rebollo J.F. (1987). Turismo y urbanización en el litoral alicantino. Alicante: Instituto Juan Gil Albert.

Vera Rebollo J.F. (1999). El modelo turístico de la marina Alta: apuntes para una nueva etapa desde la sostenibilidad como referencia. En Jornadas del Institut d'Estudis Comarcals de la Marina Alta, mayo de 1999.

Vera Rebollo J.F. (2005). Náutica de recreo y turismo: aspectos ambientales. Una aproximación desde la situación de la Comunidad Valenciana. En Blanquer D.V. (coord.), Salud, deporte y turismo (pp. 33-61). Castellón: Tirant lo Blanch.

Vera Rebollo J.F. y Baños Castiñeira C.J. (2010). Renovación y reestructuración de los destinos turísticos consolidados del litoral: las prácticas recreativas en la evolución del espacio turístico. Boletín de la Asociación de Geógrafos Españoles, 53, 329-353. 